Article

\title{
Optimization of Chitosan Glutaraldehyde-Crosslinked Beads for Reactive Blue 4 Anionic Dye Removal Using a Surface Response Methodology
}

\author{
Johanna Galan ${ }^{1}$, Jorge Trilleras 2 (), Paula A. Zapata ${ }^{3}\left(\mathbb{D}\right.$, Victoria A. Arana ${ }^{1, *(1)}$ and \\ Carlos David Grande-Tovar $4, *$ (D) \\ 1 Grupo de Investigación Ciencias, Educación y Tecnología-CETIC, Programa de Química, Universidad del \\ Atlántico, Carrera 30 No 8-49, Puerto Colombia 081008, Colombia; jgalan@mail.uniatlantico.edu.co \\ 2 Grupo de Compuestos Heterociclicos, Programa de Química, Universidad del Atlántico, Carrera 30 No 8-49, \\ Puerto Colombia 081008, Colombia; jorgetrilleras@mail.uniatlantico.edu.co \\ 3 Grupo de Polímeros, Facultad de Química y Biología, Universidad de Santiago de Chile, USACH, Casilla 40, \\ Correo 33, Santiago 9170020, Chile; paula.zapata@usach.cl \\ 4 Grupo de Investigación de Fotoquímica y Fotobiología, Programa de Química, Universidad del Atlántico, \\ Carrera 30 No 8-49, Puerto Colombia 081008, Colombia \\ * Correspondence: victoriaarana@mail.uniatlantico.edu.co (V.A.A.); \\ carlosgrande@mail.uniatlantico.edu.co (C.D.G.-T)
}

Citation: Galan, J.; Trilleras, J.;

Zapata, P.A.; Arana, V.A.;

Grande-Tovar, C.D. Optimization of Chitosan Glutaraldehyde-

Crosslinked Beads for Reactive Blue 4

Anionic Dye Removal Using a Surface

Response Methodology. Life 2021, 11,

85. https://doi.org/10.3390/

life11020085

Received: 15 December 2020

Accepted: 21 January 2021

Published: 25 January 2021

Publisher's Note: MDPI stays neutral with regard to jurisdictional claims in published maps and institutional affiliations.

Copyright: (C) 2021 by the authors. Licensee MDPI, Basel, Switzerland. This article is an open access article distributed under the terms and conditions of the Creative Commons Attribution (CC BY) license (https:// creativecommons.org/licenses/by/ $4.0 /)$.

\begin{abstract}
The use of dyes at an industrial level has become problematic, since the discharge of dye effluents into water disturbs the photosynthetic activity of numerous aquatic organisms by reducing the penetration of light and oxygen, in addition to causing carcinogenic diseases and mutagenic effects in humans, as well as alterations in different ecosystems. Chitosan (CS) is suitable for removing anionic dyes since it has favorable properties, such as acquiring a positive charge and a typical macromolecular structure of polysaccharides. In this study, the optimization of CS beads crosslinked with glutaraldehyde (GA) for the adsorption of reactive blue dye 4 (RB4) in an aqueous solution was carried out. In this sense, the response surface methodology (RSM) was applied to evaluate the concentration of CS, GA, and sodium hydroxide on the swelling degree in the GA-crosslinked CS beads. In the same way, RSM was applied to optimize the adsorption process of the RB4 dye as a function of the initial $\mathrm{pH}$ of the solution, initial concentration of the dye, and adsorbent dose. The crosslinking reaction was investigated by scanning electron microscopy (SEM), Fourier transformed infrared spectroscopy (FTIR), and X-ray diffractometry (XRD). The design described for the swelling degree showed an $\mathrm{R}^{2}$ (coefficient of determination) adjusted of 0.8634 and optimized concentrations (CS 3.3\% w/v, GA $1.7 \% v / v$, and $\mathrm{NaOH} 1.3 \mathrm{M}$ ) that were conveniently applied with a concentration of CS at 3.0\% $w / v$ to decrease the viscosity and facilitate the formation of the beads. In the RB4 dye adsorption design, an adjusted $\mathrm{R}^{2}(0.8280)$ with good correlation was observed, where the optimized conditions were: $\mathrm{pH}=2$, adsorbent dose $0.6 \mathrm{~g}$, and initial concentration of $\mathrm{RB} 4$ dye $5 \mathrm{mg} / \mathrm{L}$. The kinetic behavior and the adsorption isotherm allowed us to conclude that the GA-crosslinked CS beads' adsorption mechanism was controlled mainly by chemisorption interactions, demonstrating its applicability in systems that require the removal of contaminants with similar structures to the model presented.
\end{abstract}

Keywords: adsorption; reactive blue 4 dye; crosslinking chitosan beads; glutaraldehyde; experimental design; swelling degree; removal efficiency

\section{Introduction}

The dyes used by different industries, such as textiles, leather, paper, and plastics, among others, is of great interest, because the discharge of dye effluents into water generate persistence, bioaccumulation, and toxicity [1]. The dye's presence in aquatic environments reduces the penetration of light and oxygen, inhibiting photosynthetic activities. Likewise, 
can potentially lead to carcinogenic and mutagenic diseases in aquatic species and humans [1,2]. It is estimated that, of the 800,000 tons of colorants produced annually, $20 \%$ ends up in water bodies in the final stages of industrial processes $[3,4]$.

Wastewater has been shown to contain dye concentrations ranging from $10 \mathrm{mg} / \mathrm{L}$ to $200 \mathrm{mg} / \mathrm{L}$ [5]. Due to this growing environmental problem, some countries, such as the United Kingdom, have incorporated restrictions and laws to regulate the concentration of colorants present in bodies of water. However, the lack of control in handling the growing situation is still evident, especially in Latin America [6,7]. In this way, it is necessary to search for technologies that allow eliminating the colorants present in the different effluents.

Among many reported techniques, the adsorption process is commonly used due to its remarkable ability to remove dyes from aqueous solutions. However, the use of some sorbents (e.g., activated carbon) can be expensive and challenging alternatives to regenerate [8].

In recent years, numerous, inexpensive, and effective alternatives have been developed, including chitosan (CS), which has attracted particular attention because it is renewable, has high availability, and does not generate toxic products [9-11]. CS is suitable for removing anionic dyes since it has favorable properties, such as acquiring a positive charge and a typical macromolecular structure of polysaccharides [12,13].

However, CS easily dissolves in an acidic medium $(\mathrm{pH}<5)$, which limits its use due to the high protonation of its amino groups, leading to instability and dissolution of the material in the medium [14]. Consequently, various physical and chemical modifications have been applied to its molecular structure, such as the formation of spherical beads, which increase the porosity of CS and improve its surface area [15]. Another alternative has been the addition of crosslinking agents, such as glutaraldehyde (GA), which allow better mechanical resistance and stability in a wide $\mathrm{pH}$ range [16]. Studies conducted by Ngah and Fatinathan [17] show how GA-crosslinked CS beads have a greater adsorption capacity to remove $p$-nitrophenol than physical modifications of CS in the form of flakes.

Likewise, the implementation of low molecular weight (LMW) CS has proven to be better biocompatible and biodegradable than high molecular weight (HMW) CS [18].

Its use at LMW provides a more excellent facility to interact with the dye because its chains are shorter and allow better access to the available adsorption sites [19]. On the other hand, although various studies have been reported on the removal of anionic dyes, there is a need to evaluate and optimize the variables that influence the processes of obtaining and adsorption of modified beads with the application of classical statistical models, a design of experiments with response surface methodology (RSM) approaches, which determine and quantify the factors that could influence the variable of interest.

Therefore, the purpose of this research was to evaluate the development of low molecular weight CS beads crosslinked with GA to maximize the removal efficiency of reactive blue dye 4 in an aqueous solution.

\section{Materials and Methods}

\subsection{Experimental Design}

A central composite experimental design (CCED) was used to evaluate the swelling degree of CS beads cross-linked with GA and the removal efficiency of the anionic dye RB4. Both designs consisted of conducting 32 randomized experiments, including duplicates. Three series of experiments were developed: (a) a factorial design $\left(2^{\mathrm{k}}\right)$ with three factors $(\mathrm{k}=3)$, each with two levels (maximum, +1 and minimum, -1$)$; $(\mathrm{b})$ axial points with coded values $\alpha=2^{\mathrm{k} / 4}= \pm 1.6817$; and (c) duplicate of the central point. For the first design, input factors were the concentration of $\mathrm{CS}, \mathrm{NaOH}$ concentration, and GA concentration. The response factor was the swelling degree. For the second design, input factors were the adsorbent dose, initial concentration of the dye, and the dye solution's $\mathrm{pH}$. The response factor was dye removal efficiency. 
The experiment design, analysis of variance (ANOVA), response surface methodology, and optimization were performed using Statgraphics Centurion XVI software (StatPoint Technologies, Inc., The Plains, USA) [20]. Second-order mathematical models were created to optimize the factors studied, according to Equation (1) [21].

$$
Y=\beta_{0}+\sum_{i=1}^{k} \beta_{i} X_{i}+\sum_{i=1}^{k} \beta_{i i} X_{i}^{2}+\sum_{i=1} \sum_{<j=1} \beta_{i j} X_{i} X_{j}+\varepsilon
$$

where $Y$ is the adjusted response variable, $i, j$ linear, and quadratic coefficients, $\beta$ is the regression coefficient, $k$ is the number of optimized factors, and $\varepsilon$ the experimental error.

\subsection{Preparation of GA-Crosslinked CS Beads}

Concentrations between $1.7(\% w / v)$ and $3.3(\% w / v)$ of CS (75-85\% deacetylation degree and low molecular weight of 50-190 kDa, Merck KGaA, Darmstadt) solution were prepared in $1(\% v / v)$ acetic acid solution and homogenized with a digital disperser (ULTRATURRAX IKA T-25, Merck KGaA, Darmstadt, Germany).

The above CS solutions were added dropwise into sodium hydroxide solutions with a concentration range of $0.7 \mathrm{M}$ to $2.3 \mathrm{M}$, under constant stirring, to allow the formation of CS beads with controlled spherical size. The beads formed were removed from the solution, washed with distilled water until a neutral $\mathrm{pH}$ value was obtained. The CS beads were immersed for $12 \mathrm{~h}$ in $25 \mathrm{~mL}$ of GA solutions with a concentration range of $1.7(\% \mathrm{v} / \mathrm{v})$ to $3.3(\% v / v)$. The crosslinked beads were filtered from the solution, washed vigorously with distilled water to remove any unreacted particles, and dried in an oven at $60{ }^{\circ} \mathrm{C}$ for $10 \mathrm{~h}$ [22].

\subsection{Swelling Test of Crosslinked Beads}

One gram of GA-crosslinked CS beads obtained in each experiment was immersed in distilled water at room temperature and neutral $\mathrm{pH}$. After $24 \mathrm{~h}$, the beads were filtered, excess water was removed with filter paper, and weighed to constant weight. The swelling degree was calculated with Equation (2).

$$
\text { Swelling degree }(\%)=\frac{w_{1}-w_{0}}{w_{0}} \times 100
$$

where $W_{0}(\mathrm{~g})$ is the dry mass and $W_{1}(\mathrm{~g})$ is the wet mass after $24 \mathrm{~h}$ [23]. Furthermore, the crosslinked beads' behavior was studied at $\mathrm{pH}$ values of 3 and 10, adjusting with $\mathrm{NaOH}$ $(0.1 \mathrm{M})$ and $\mathrm{HCl}(0.1 \mathrm{M})$.

\subsection{Calibration Curve of RB4 Dye}

Standard solutions were prepared at different concentrations of the RB4 dye $(1,5,15$, $25,35,45,55,60,65,70 \mathrm{mg} / \mathrm{L})$. The above solutions' absorbances were measured in the UV-VIS spectrophotometer (Mapada UV-1600, Shanghai, China), at a maximum length of $599 \mathrm{~nm}$. The model was estimated using linear regression analysis to obtain the dye concentrations in the adsorption processes.

\subsection{Adsorption Study of RB4 Dye}

A stock solution of $500 \mathrm{mg} / \mathrm{L}$ of the RB4 dye was prepared. From the stock solution, solutions were prepared in a range of $5 \mathrm{mg} / \mathrm{L}$ to $55 \mathrm{mg} / \mathrm{L}$. Each experiment's $\mathrm{pH}$ was adjusted with minimum and maximum values of 2.0 and 7.0 by adding $\mathrm{HCl}(0.01 \mathrm{M})$ and $\mathrm{NaOH}(0.01 \mathrm{M})$. Next, $25 \mathrm{~mL}$ aliquots were taken, and their initial absorbances were measured at a maximum length of $599 \mathrm{~nm}$. Subsequently, specific amounts from $0.1 \mathrm{~g}$ to $0.6 \mathrm{~g}$, corresponding to a dose of adsorbent between $0.1 \mathrm{~g} / 25 \mathrm{~mL}$ and $0.6 \mathrm{~g} / 25 \mathrm{~mL}$, were added. The samples were placed in the dark with shaking at a speed of $400 \mathrm{rpm}$ to prevent dye photolysis. After $48 \mathrm{~h}$, following beads filtration, the absorbance of the RB4 dye in the supernatant was measured. The dye removal efficiency was determined with Equation (3). 


$$
R(\%)=\frac{\left(C_{\mathrm{o}}-C_{\mathrm{e}}\right)}{\mathrm{C}_{\mathrm{o}}} \times 100
$$

where $R(\%)$ is the removal efficiency, $C_{\mathrm{o}}$ and $C_{\mathrm{e}}(\mathrm{mg} / \mathrm{L})$ are the initial concentration and the final or equilibrium concentration of the anionic dye RB4 [9].

\subsection{Characterization of GA-Crosslinked CS Beads}

Scanning electron microscopy (SEM) (JSM-6490LA, JEOL, Tokyo, Japan) and Fourier transformed infrared spectroscopy—attenuated total reflectance (FTIR-ATR) (IRAffinity-1, Shimadzu, Kyoto, Japan) were used to determine the surface morphology of the adsorbents and the presence of functional groups. The crystalline phase of the cross-linked beads was detected by X-ray diffractometry (XRD) (PANalytical X'Pert PRO, Malvern Panalytical, Malvern, United Kingdom) using radiation of $\mathrm{Cu} \mathrm{K} \alpha 1(1.540598 \AA)$ and $\mathrm{K} \alpha 2(1.544426 \AA)$, in a range of $2 \theta$ comprised from $5^{\circ}$ to $50^{\circ}$. Equation (4) shows the percentage of crystallinity $\left(\mathrm{Xc}_{\mathrm{c}} \%\right)$ of each pearl obtained from their diffractograms using the Nara-Komiya methodology [24].

$$
X_{c}(\%)=\frac{\left(\mathrm{A}_{\mathrm{c}}\right)}{\left(\mathrm{A}_{\mathrm{T}}\right)} \times 100
$$

where $A_{c}$ is the area of the peaks representing the crystalline regions and $A_{T}$ is the total area of the crystalline and amorphous region.

\subsection{Kinetic Experiment}

A $500 \mathrm{mg} / \mathrm{L}$ stock solution of the RB4 dye was used to take $25 \mathrm{~mL}$ of a $35 \mathrm{mg} / \mathrm{L}$ solution, and its initial absorbance was measured. Then $0.4 \mathrm{~g} / 25 \mathrm{~mL}$ of GA-crosslinked CS beads were added. This solution was stored in the dark under constant stirring at $400 \mathrm{rpm}$ and room temperature. Twenty absorbance measurements were taken at different time intervals during $48 \mathrm{~h}$, taking small aliquots of the stored solution. The amount of equilibrium adsorption, $Q_{e}(\mathrm{mg} / \mathrm{g})$, was calculated from Equation (5) [25]. The kinetic models described in Table $\mathrm{S} 1$ of the supporting information were analyzed using OriginPro 8 software (Origin Lab Corporation, Northampton, MA, USA).

$$
\mathrm{Q}_{\mathrm{e}}=\frac{\left(C_{\mathrm{o}}-C_{\mathrm{e}}\right) \times V}{W}
$$

where $C_{\mathrm{o}}$ and $C_{\mathrm{e}}(\mathrm{mg} / \mathrm{L})$ are the liquid-phase concentrations of dye initially and at equilibrium, respectively, $V(\mathrm{~L})$ is the volume of the dye, and $W(\mathrm{~g})$ is the weight of the adsorbent.

\subsection{Isothermal Experiment}

RB4 dye solutions of $5 \mathrm{mg} / \mathrm{L}$ to $65 \mathrm{mg} / \mathrm{L}$ with a $\mathrm{pH}$ adjusted to 3.0 were prepared from the $500 \mathrm{mg} / \mathrm{L}$ stock solution. The isothermal experiments were carried out under the same conditions as the kinetic experiment. After $48 \mathrm{~h}$ of constant stirring, the beads were separated by filtration, and the final absorbances were measured. Subsequently, the adsorption equilibrium models described in Table S2 of the supporting information were plotted using OriginPro 8 software (Origin Lab Corporation, Northampton, MA, USA). The adsorption capacity obtained at equilibrium was determined with Equation (5).

\section{Results}

\subsection{Optimization for the Preparation of Cross-Linked CS Beads}

The optimization of the GA-crosslinked CS beads was evaluated on the swelling degree. The swelling degree accounts for the expansion of chitosan's porous structure, which allows the interaction of the dye molecules with the adsorption sites [12]. Table 1 shows the complete experimental design of obtaining the GA-crosslinked CS beads and their respective responses to the degree of swelling obtained in each experimental run. 
Table 1. Experimental design matrix and response results for glutaraldehyde (GA)-crosslinked chitosan (CS) beads preparation.

\begin{tabular}{cccccc}
\hline \multicolumn{2}{c}{ Factors } & \multicolumn{2}{c}{ Response } \\
\hline Run & CS $(\boldsymbol{\%} \boldsymbol{w} / \boldsymbol{v})$ & GA $(\boldsymbol{\%}$ v/v) & NaOH $(\mathbf{M})$ & \multicolumn{2}{c}{ Swelling Degree (\%) } \\
\hline $\mathbf{1}$ & 2.5 & 2.5 & 1.5 & 19.23 & 18.83 \\
$\mathbf{2}$ & 3.0 & 3.0 & 2.0 & 25.73 & 25.00 \\
$\mathbf{3}$ & 2.5 & 3.3 & 1.5 & 22.50 & 21.34 \\
$\mathbf{4}$ & 3.0 & 3.0 & 1.0 & 23.58 & 23.06 \\
$\mathbf{5}$ & 2.0 & 2.0 & 1.0 & 30.07 & 29.82 \\
$\mathbf{6}$ & 2.0 & 3.0 & 1.0 & 24.15 & 26.15 \\
$\mathbf{7}$ & 2.5 & 2.5 & 2.3 & 17.57 & 17.23 \\
$\mathbf{8}$ & 2.5 & 2.5 & 1.5 & 18.06 & 19.51 \\
$\mathbf{9}$ & 3.0 & 2.0 & 1.0 & 33.99 & 35.01 \\
$\mathbf{1 0}$ & 1.7 & 2.5 & 1.5 & 23.15 & 21.80 \\
$\mathbf{1 1}$ & 2.5 & 2.5 & 0.7 & 18.92 & 19.32 \\
$\mathbf{1 2}$ & 2.0 & 3.0 & 2.0 & 24.88 & 25.12 \\
$\mathbf{1 3}$ & 2.0 & 2.0 & 2.0 & 28.47 & 26.11 \\
$\mathbf{1 4}$ & 3.0 & 2.0 & 2.0 & 33.16 & 34.03 \\
$\mathbf{1 5}$ & 2.5 & 1.7 & 1.5 & 40.54 & 40.12 \\
$\mathbf{1 6}$ & 3.3 & 2.5 & 1.5 & 39.71 & 39.88 \\
\hline
\end{tabular}

The contributions of the operational and interaction factors that influenced the swelling degree were evaluated by ANOVA (Table 2). The factors in order of significance and contribution at a confidence level of $95 \%(p<0.05)$ were: CS concentration $(A)$, GA concentration (B), quadratic interaction of CS concentration (AA), quadratic interaction of GA concentration $(\mathrm{BB})$, interaction concentrations of $\mathrm{CS}$, and $\mathrm{GA}(\mathrm{AB})$.

Table 2. ANOVA results for GA-crosslinked CS beads preparation experiments.

\begin{tabular}{|c|c|c|c|c|c|}
\hline Factors & Sum of Squares & $\mathrm{df}^{\mathrm{a}}$ & Mean Square & F & Value- $p^{b}$ \\
\hline A: (CS) & 215.986 & 1 & 215.986 & 30.47 & 0.0000 \\
\hline B: (GA) & 481.445 & 1 & 481.445 & 67.93 & 0.0000 \\
\hline $\mathrm{C}:(\mathrm{NaOH})$ & 2.88398 & 1 & 2.88398 & 0.410 & 0.5304 \\
\hline $\mathrm{AA}$ & 373.589 & 1 & 373.589 & 52.71 & 0.0000 \\
\hline $\mathrm{AB}$ & 38.7195 & 1 & 38.7195 & 5.460 & 0.0294 \\
\hline $\mathrm{AC}$ & 3.65766 & 1 & 3.65766 & 0.520 & 0.4804 \\
\hline $\mathrm{BB}$ & 373.001 & 1 & 373.001 & 52.63 & 0.0000 \\
\hline $\mathrm{BC}$ & 7.77016 & 1 & 7.77016 & 1.100 & 0.3070 \\
\hline $\mathrm{CC}$ & 0.07039 & 1 & 0.07039 & 0.010 & 0.9216 \\
\hline Blocks & 0.49252 & 1 & 0.49252 & 0.070 & 0.7946 \\
\hline Total error & 148.836 & 21 & 7.08744 & & \\
\hline Total (corrected) & 1608.0 & 31 & & & \\
\hline $\mathrm{R}^{2}$ & 90.74 & & & & \\
\hline Adj.- $R^{2}$ & 86.34 & & & & \\
\hline Adequate Precision & 14.11 & & & & \\
\hline
\end{tabular}

a degree of freedom, ${ }^{\mathrm{b}}$ considered significant when $p<0.050$.

The model's effectiveness was evaluated based on the coefficient of determination, $\mathrm{R}^{2}$ and adjusted $R^{2} . R^{2}(90.74 \%)$ values and adjusted $R^{2}(86.34 \%)$ indicated a good correlation between the input and output variables [26]. Adequate precision (14.11) indicated an adequate signal, and this model can be used to navigate the design space. Similarly, based on the experimental data, the adjusted quadratic model equation was established (Equation (6)). 


$$
\begin{aligned}
\text { Swelling degree } & (\%) \\
& =229.35-71.4949 \mathrm{~A}-86.7575 \mathrm{~B}-11.6602 \mathrm{C} \\
& +17.961 \mathrm{~A}^{2}-6.2225 \mathrm{AB}+1.9125 \mathrm{AC}+17.9471 \mathrm{~B}^{2} \\
& +2.7875 \mathrm{BC}-0.246556 \mathrm{C}^{2}
\end{aligned}
$$

A is the concentration of CS, B is the concentration of GA, and C is NaOH concentration. The Pareto chart plots the standardized effects of each factor and their interactions. The positive (+) or negative (-) effect on the response factor is given by the increase in the factor level [27]. Figure 1 represents the standardized effects for the swelling degree. The GA concentration factor was the variable that had the most significant negative influence, and the CS concentration factor was the variable that had the most significant favorable influence on the response. The increase in GA concentration produced a higher consumption of the amino groups in the crosslinking reaction. Consequently, the crosslinked CS beads had a lower ability to bind to water molecules due to reduced active sites [28,29].

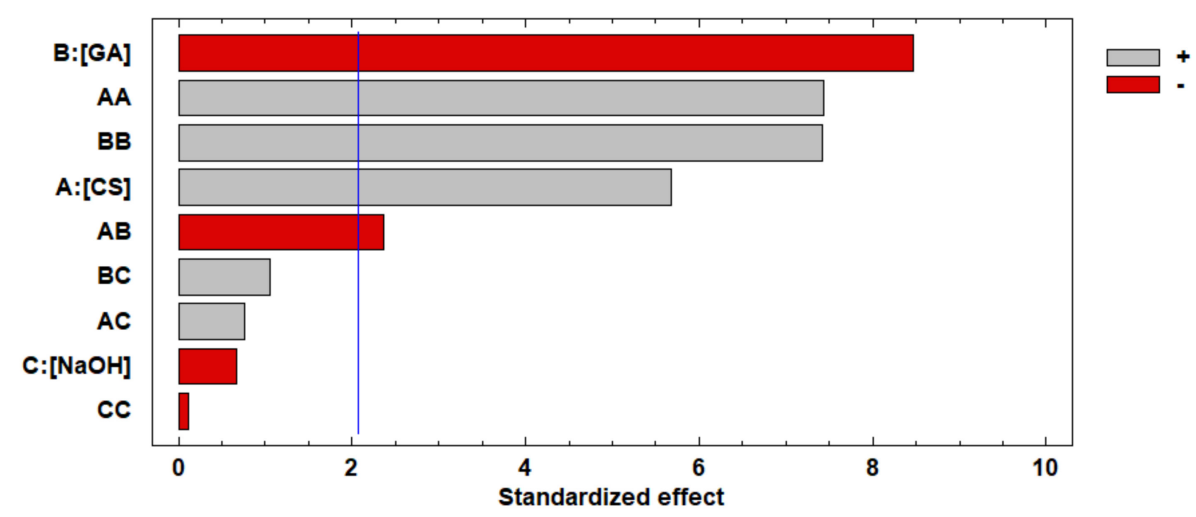

Figure 1. Pareto chart of standardized effects for response variable swelling degree.

On the other hand, the swelling degree was not affected by the $\mathrm{NaOH}$ concentration. This result might be due to the limited range in which this input variable was studied. A reported study indicated that when the $\mathrm{NaOH}$ concentration is increased in a range from 1 to $5 \mathrm{M}$, it is possible to reduce the water content in the porous beads [30]. That is, the percentage of the swelling degree decreases. Additionally, AA and BB's significant quadratic factors indicated the presence of curvatures in the model and a possible optimal value of the swelling (\%) degree for certain variables analyzed.

The response surface plot of Figure 2 shows that the swelling degree at neutral $\mathrm{pH}$ is favored with increasing CS concentration. The maximum predicted swelling of $60.65 \%$ was reached with a concentration of $3.3(\% w / v)$ of $\mathrm{CS}, 1.7(\% v / v)$ of GA, and $1.3 \mathrm{M} \mathrm{NaOH}$. Similarly, the mentioned conditions were validated, obtaining a 50\% swelling degree.

The GA-crosslinked CS beads response model was recommended for prediction purposes within the selected range since it translated more than $70 \%$ of the response in terms of adjusted $\mathrm{R}^{2}(0.8634)$. However, the surface graph shows that the most suitable treatment was found towards a point outside the experimental region, suggesting expanding the study range in the direction where RSM indicated the possible best treatment (towards the region of warm colors). It should be noted that increasing the concentration of CS implies an increase in viscosity and a more challenging bead formation. Therefore, the experimental adsorption design applied in this work was carried out at concentrations of $3.0(\% w / v)$ of $\mathrm{CS}, 1.7(\% v / v)$ of $\mathrm{GA}$, and $1.3 \mathrm{M}$ of $\mathrm{NaOH}$, where the swelling degree obtained was $48 \%$.

On the other hand, the cross-linked beads' swelling was determined under the influence of acidic $\mathrm{pH}(3)$ and basic $\mathrm{pH}(10)$, reaching swelling percentages of $90 \%$ and $14 \%$, respectively. This behavior was explained because CS is a weak base with a $p K a$ of around 6.4 [31]. Therefore, at a $\mathrm{pH}$ value below $\mathrm{pKa}$, the amino groups in the CS molecules ionize 
into ammonium ions, acting as repulsive forces between polymer chains, allowing a higher swelling degree [28].

On the other hand, at a $\mathrm{pH}$ above $\mathrm{pKa}$, a more significant number of $\mathrm{OH}^{-}$ions are produced in the medium, and consequently, the protonation of the amino groups is minimal, leading to a low swelling degree [28].

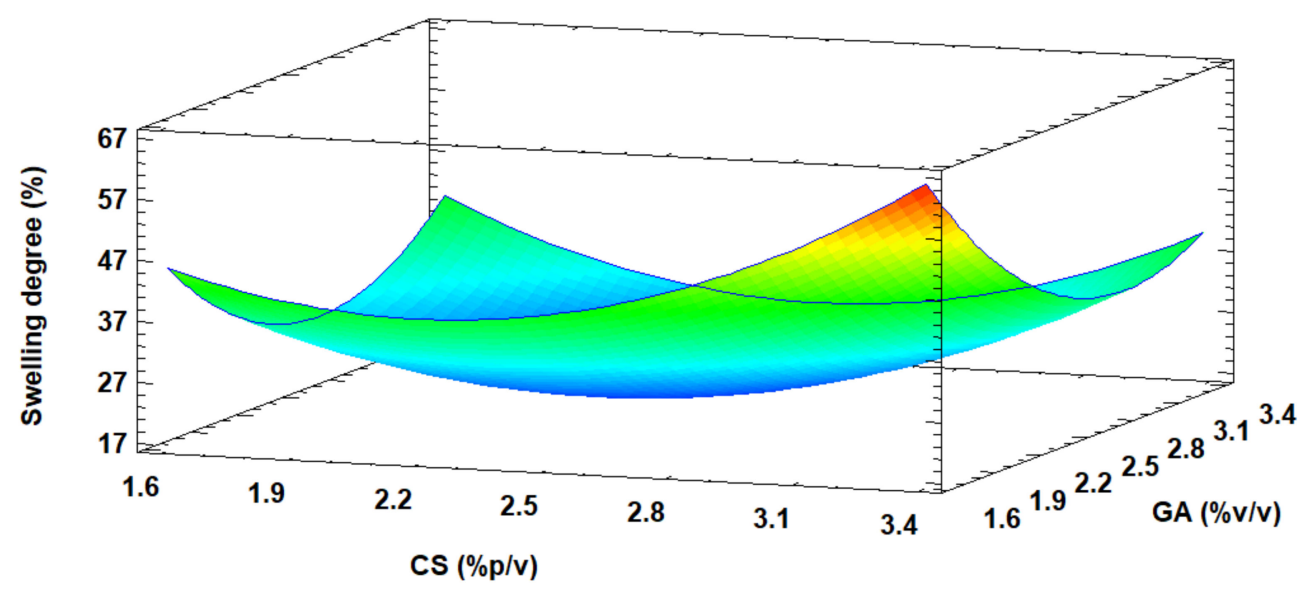

Figure 2. Three-dimensional (3D) response surface plot for optimizing the swelling degree of GAcrosslinked CS beads. $\mathrm{NaOH}=1.5 \mathrm{M}$.

\subsection{Preparation of the GA-Crosslinked CS Beads}

Obtaining the GA-crosslinked CS beads required an acid-base reaction and, subsequently, cross-linking. Initially, the CS amino groups' protonation was carried out in acetic acid solution (Figure 3a). Subsequently, a neutralization reaction took place due to the addition of a $\mathrm{NaOH}$ solution, which favored the formation of uniform, spherical, and porous gel beads (Figure 3b) [30]. Finally, with the crosslinking agent (GA) addition, the CS amino groups reacted with generating chemical cross-links of imines (Figure 3c). However, several studies have indicated that the CS-GA reaction can undergo self-oligomerization by aldol condensation, producing a longer chain in the crosslinking structure [32]. In this aspect, the crosslinking reaction generated an orange color that corresponded to the presence of unsaturated bonds such as $\mathrm{C}=\mathrm{N}$ (imine), $\mathrm{C}=\mathrm{C}$ (double bond), and $\mathrm{C}=\mathrm{O}$ (aldehyde). This increase in unsaturated bonds can lead to color intensification for some beads [31-34].

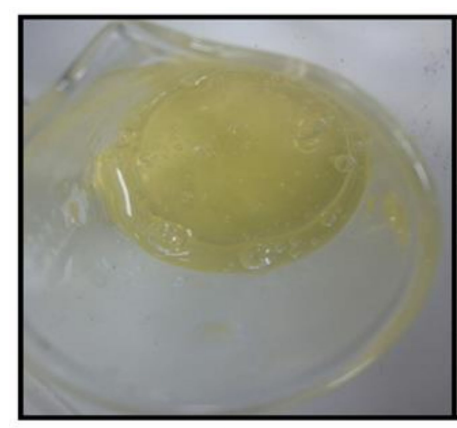

a)

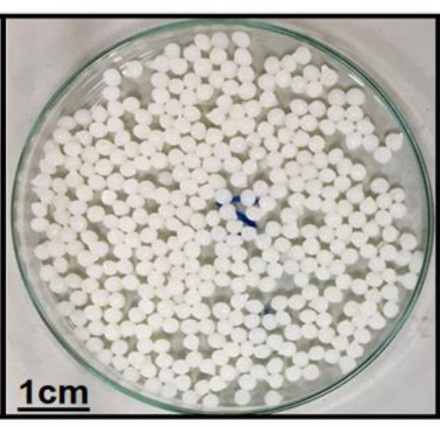

b)

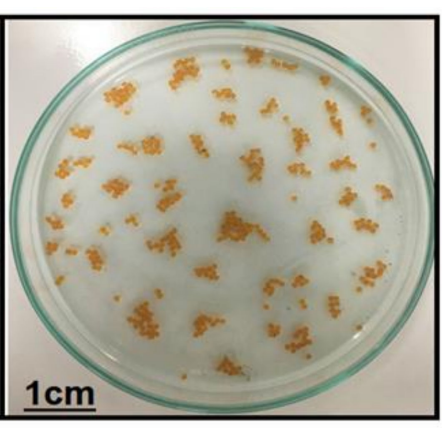

c)

Figure 3. The appearance of $\mathrm{CS}$ in the process of obtaining the beads; (a) $\mathrm{CS}-\mathrm{CH}_{3} \mathrm{COOH}$ solution, (b) CS beads precipitated in $\mathrm{NaOH}_{(\mathrm{aq})}$; (c) final product of the beads cross-linked with GA.

\subsection{Optimization for the Adsorption of the RB4 Dye in an Aqueous Solution}

A calibration curve (Figure 4) was prepared at a $\lambda$ max of $599 \mathrm{~nm}$ to quantify the RB4 dye experiments. The quality of the curve was evaluated based on the determination coefficient $R^{2}$. The value of $R^{2}(99.95 \%)$ indicated that the experimental points were correctly adjusted to the mathematical model of the equation. 


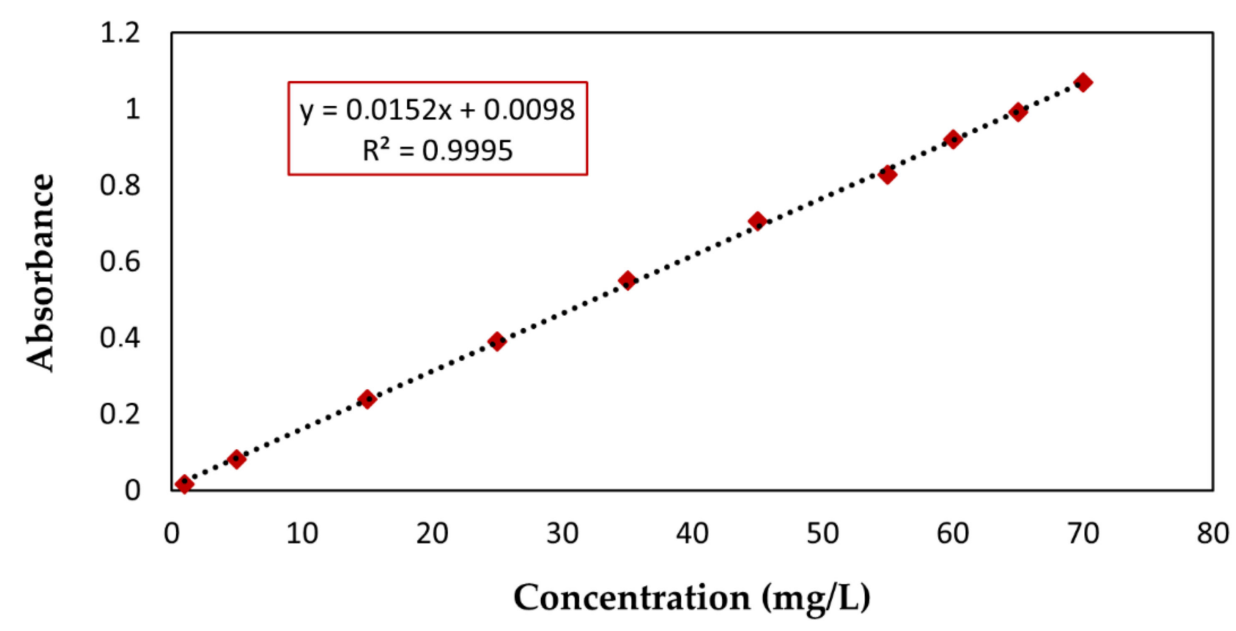

Figure 4. Calibration curve for RB4 dye measured at $599 \mathrm{~nm}$. Concentration range of $1 \mathrm{mg} / \mathrm{L}$ to $70 \mathrm{mg} / \mathrm{L}$.

In the adsorption processes, the GA-crosslinked CS beads were prepared from a concentration of CS at $3.0(\% w / v), \mathrm{GA}$ at $1.7(\% v / v)$, and $\mathrm{NaOH}$ at $1.3 \mathrm{M}$. Table 3 shows the matrix of CCED experimental variables with RB4 removal efficiency responses.

Table 3. Experimental design matrix and response results for RB4 dye adsorption on GA-crosslinked CS beads.

\begin{tabular}{|c|c|c|c|c|c|}
\hline \multicolumn{4}{|c|}{ Factors } & \multicolumn{2}{|c|}{ Response } \\
\hline \multirow{2}{*}{ Run } & \multirow{2}{*}{$\mathrm{AD}(\mathrm{g})$} & \multirow{2}{*}{ pH } & \multirow{2}{*}{ [RB4] (mg/L) } & \multicolumn{2}{|c|}{ Removal Efficiency (\%) } \\
\hline & & & & 1 & 2 \\
\hline 1 & 0.35 & 4.5 & 55 & 31.81 & 32.71 \\
\hline 2 & 0.50 & 3.0 & 45 & 74.05 & 73.39 \\
\hline 3 & 0.50 & 6.0 & 15 & 90.00 & 79.59 \\
\hline 4 & 0.35 & 4.5 & 5,0 & 78.22 & 70.99 \\
\hline 5 & 0.20 & 6.0 & 15 & 42.84 & 47.98 \\
\hline 6 & 0.20 & 3.0 & 45 & 46.06 & 42.62 \\
\hline 7 & 0.35 & 2.0 & 30 & 98.34 & 96.19 \\
\hline 8 & 0.35 & 4.5 & 30 & 28.87 & 28.48 \\
\hline 9 & 0.60 & 4.5 & 30 & 50.06 & 49.72 \\
\hline 10 & 0.20 & 6.0 & 45 & 14.75 & 13.21 \\
\hline 11 & 0.35 & 7.0 & 30 & 7.465 & 9.566 \\
\hline 12 & 0.50 & 3.0 & 15 & 100.0 & 99.72 \\
\hline 13 & 0.35 & 4.5 & 30 & 53.76 & 43.41 \\
\hline 14 & 0.20 & 3.0 & 15 & 97.49 & 94.77 \\
\hline 15 & 0.10 & 4.5 & 30 & 9.525 & 9.853 \\
\hline 16 & 0.50 & 6.0 & 45 & 21.11 & 24.46 \\
\hline
\end{tabular}

AD: Adsorbent Dose; [RB4]: concentration of RB4.

According to Table 4, the analysis of variance showed an $\mathrm{R}^{2}$ and an adjusted $\mathrm{R}^{2}$ determination coefficient of $88.35 \%$ and $82.80 \%$, respectively, indicating that the main effects $(A, B, C)$ and the quadratic effects $\left(B^{2}\right.$ and $\left.C^{2}\right)$ are significantly different from zero at a $95 \%$ confidence level $(p<0.05)$. Adequate precision (14.03) indicated an adequate signal, and this model can be used to navigate the design space. 
Table 4. ANOVA results for RB4 dye adsorption experiments on GA-crosslinked CS beads.

\begin{tabular}{|c|c|c|c|c|c|}
\hline Factors & Sum of Squares & $\mathrm{Df}^{\mathrm{a}}$ & Mean Square & $\mathbf{F}$ & Value- $p^{b}$ \\
\hline A: Adsorbent dose & 3247.78 & 1 & 3247.78 & 18.92 & 0.0003 \\
\hline $\mathrm{B}: \mathrm{pH}$ & $12,860.1$ & 1 & $12,860.1$ & 74.93 & 0.0000 \\
\hline $\mathrm{C}:(\mathrm{RB} 4)$ & 8618.51 & 1 & 8618.51 & 50.22 & 0.0000 \\
\hline AA & 0.878497 & 1 & 0.878497 & 0.01 & 0.9436 \\
\hline $\mathrm{AB}$ & 56.9199 & 1 & 56.9199 & 0.33 & 0.5708 \\
\hline $\mathrm{AC}$ & 6.09537 & 1 & 6.09537 & 0.04 & 0.8523 \\
\hline BB & 1302.50 & 1 & 1302.50 & 7.59 & 0.0119 \\
\hline $\mathrm{BC}$ & 60.1373 & 1 & 60.1373 & 0.35 & 0.5602 \\
\hline $\mathrm{CC}$ & 1362.49 & 1 & 1362.49 & 7.94 & 0.0103 \\
\hline Blocks & 23.9524 & 1 & 23.9524 & 0.14 & \\
\hline Total error & 3604.16 & 21 & 171.627 & & \\
\hline Total & $30,923.8$ & 31 & & & \\
\hline $\mathrm{R}^{2}$ & 88.35 & & & & \\
\hline Adj.-R ${ }^{2}$ & 82.80 & & & & \\
\hline Adequate Precision & 14.03 & & & & \\
\hline
\end{tabular}

Based on the experimental data, a second-order polynomial equation (Equation (7)) was used to predict the removal efficiency of the RB4 dye. The mathematical model obtained showed high predictive quality since the predicted values and the experimental values presented a good correlation.

$$
\begin{aligned}
& \text { Removal efficiency }(\%) \\
& =222.06+36.428 \mathrm{~A}-48.3522 \mathrm{~B}-2.98722 \mathrm{C}+9.67765 A^{2}+8.3828 A B \\
& -0.27432 A C+3.72639 B^{2}-0.0861647 B C \\
& +0.0381125 C^{2}
\end{aligned}
$$

where $A(\mathrm{~g})$ is the adsorbent dose, $B$ is the $\mathrm{pH}$, and $C(\mathrm{mg} / \mathrm{L})$ is the concentration of the RB4 dye.

Figure 5 shows the Pareto chart of standardized effects for RB4 dye removal with the GA-crosslinked CS beads. The $\mathrm{pH}(\mathrm{B})$ and concentration of the RB4 dye (C) were the most significant factors affecting the response variable. Both factors showed negative signs, which indicates that the percentage of removal of the dye increased with the decrease in its levels. In contrast, the adsorbent dose (A) positively affected the percentage of removal efficiency of RB4 when the values in its levels were increased. Likewise, the quadratic interactions (CC and $\mathrm{BB}$ ) had a significantly small effect, indicating a small curvature in the model.

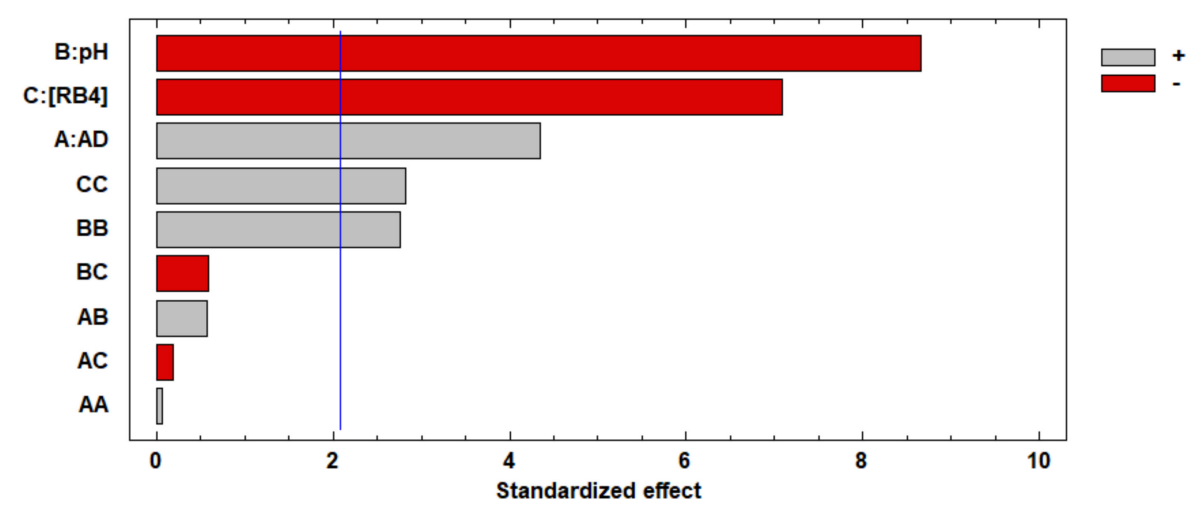

Figure 5. Pareto chart of standardized effects for response variable RB4 dye removal efficiency. AD: adsorbent dose. 
The solution's $\mathrm{pH}$ is a variable of great importance in the dye's removal efficiency since it can change the adsorbent's surface charge to influence the adsorption process [35]. When the RB4 dye solution had low $\mathrm{pH}$ values, protonation of the amino groups occurred due to the high concentration of protons available in the solution. Protonation of the amino groups led to increased interaction capacity between negatively charged dye molecules and the GA-crosslinked CS beads' protonated surface. In contrast, when the dye solution took on high $\mathrm{pH}$ values, the protonation of the available amino groups decreased, and consequently, the interaction capacity between the adsorbate and the adsorbent was reduced [36-38]. On the other hand, it is crucial to determine the dye species that predominate with the $\mathrm{pH}$ change since each species may react differently. According to reported studies [39], the RB4 dye has three predominant and deprotonated species in the $\mathrm{pH}$ range of 4 and 14 with estimated $p K a$ values equal to $0.80,1.44,7.83$, and 12.05 . These data show that at $\mathrm{pH} 4$, the two sulfonate groups are dissociated. At a pH 10 and 14, the amino groups and dissociated sulfonate groups coexist. Therefore, the acidity of the sulfonate groups in the structure of the RB4 dye maintains the anionic charges throughout the $\mathrm{pH}$ range, and consequently, the dye solution's pH will affect the adsorption rate. In this sense, in the adsorption with GA-crosslinked CS beads, at a pH of 3, it could be assumed that the sulfonate groups are the species that interact with the adsorbent through an electrostatic interaction [40].

On the other hand, the adsorbent and adsorbate concentrations influenced the efficiency of the removal process. An increase in the amount of GA-crosslinked CS beads meant more significant adsorption sites on the adsorbent's surface [41-43]. On the contrary, a high dye concentration generated a high electrostatic repulsion between the dye molecules and the free adsorption sites' saturation, which caused low adsorption of the adsorbate molecules on the surface GA-crosslinked CS beads [44].

Figure 6 , the 3D response surface plot for the interaction of the initial concentration of the RB4 dye and $\mathrm{pH}$ is illustrated, at an adsorbent dose of $0.35 \mathrm{~g} / 25 \mathrm{~mL}$ as a central value. It was evidenced that the dye's initial concentration influenced the saturation of the adsorption sites in the GA-crosslinked CS beads and that the $\mathrm{pH}$ of the solution was responsible for the surface charge of the adsorbent. Therefore, its interaction effect was influential in the response. The dye's removal efficiency conditions were maximized: $0.6 \mathrm{~g} / 25 \mathrm{~mL}$ of adsorbent dose, $\mathrm{pH} 2$, and an initial concentration of adsorbent of $5 \mathrm{~g} / \mathrm{L}$. The maximum response value predicted by the adjusted model was $100 \%$ removal efficiency of the RB4 dye. The operating conditions mentioned were experimentally applied to confirm the optimized treatment, and it was evidenced that the dye was entirely removed.

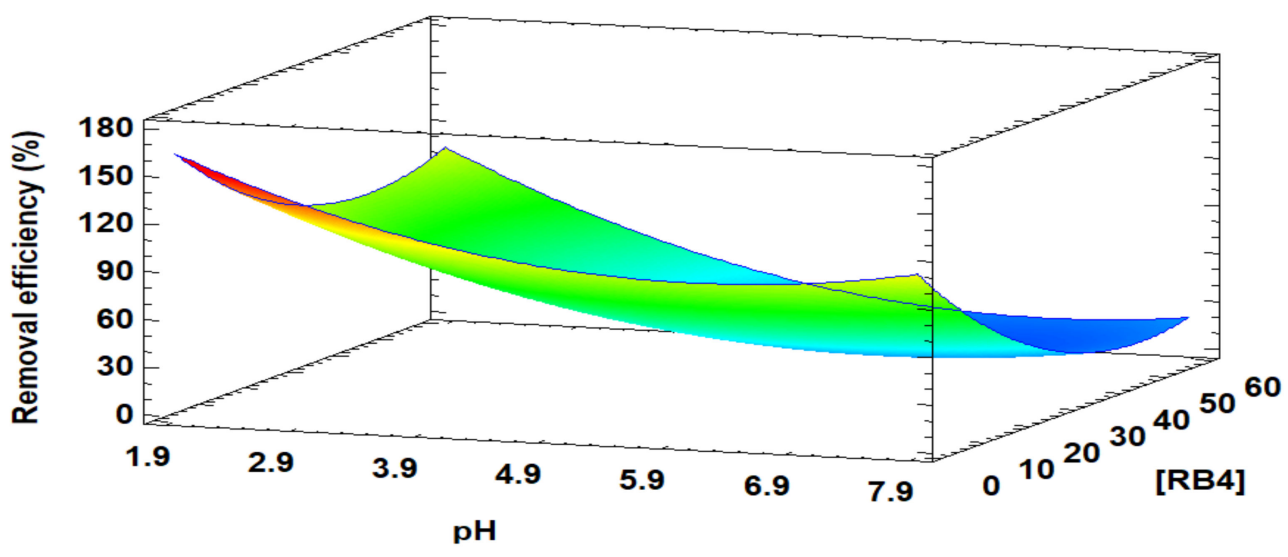

Figure 6. The 3D response surface plot for optimization of RB4 dye removal efficiency. Adsorbent dose: $0.35 \mathrm{~g} / 25 \mathrm{~mL}$.

\subsection{Characterization of the GA-Crosslinked CS Beads}

For the modified CS beads' characterization, morphological analysis was carried out by SEM, FT-IR, and XRD. 
The SEM analysis showed that the treatment of the GA-crosslinked CS beads modifies their surface texture. Figure 71a-3a shows the non-crosslinked CS beads' interior, GAcrosslinked CS beads, and GA-crosslinked CS beads after adsorption. It was evidenced that inside the adsorbents, all had a smooth surface. This confirmed that the chemical modification and adsorption processes did not affect the internal structure of the material. The CS images on the surface Figure 71b-1d show a smooth texture, while the CS beads Figure $72 b-2 d$ show a rough and porous surface structure. This result indicated that GA had chemically modified the CS beads. In contrast, the surface of GA-crosslinked CS beads after adsorption was slightly more compact, as a product of the adsorption of molecules of the dye RB4 Figure 73b-3d [45,46].

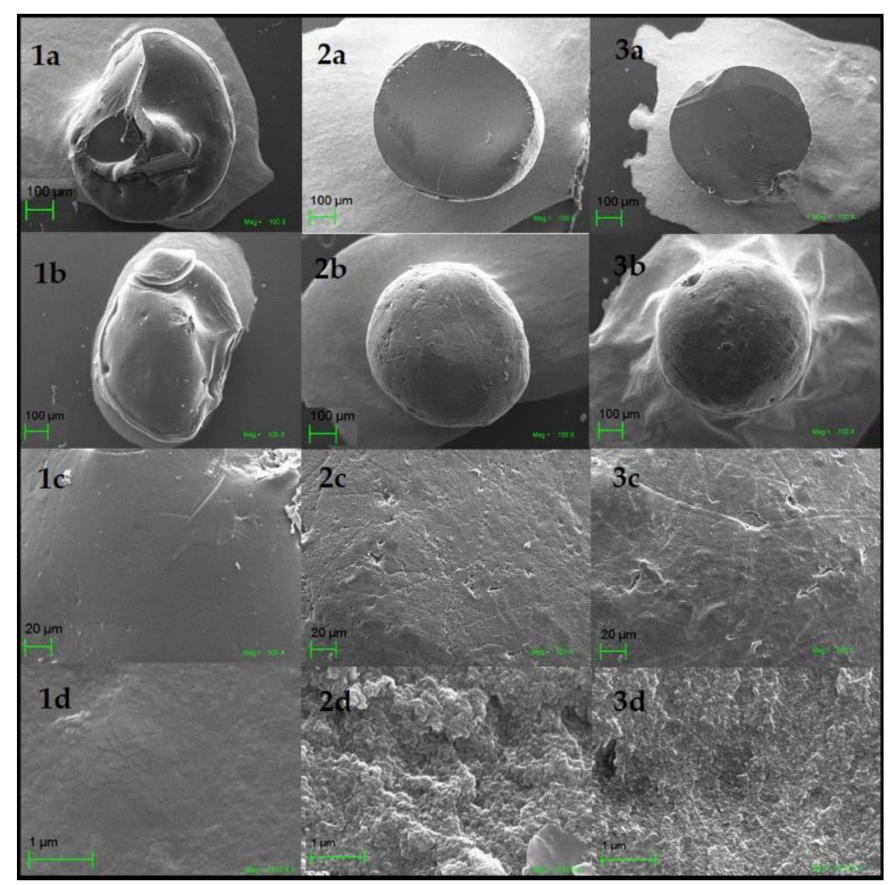

Figure 7. SEM images. Morphology of non-crosslinked CS beads, cross-section: (1a) at $100 \times$, surface area: (1b) at $100 \times,(\mathbf{1 c})$ at $500 \times,(\mathbf{1 d})$ at 25,000 × GA-crosslinked CS beads, cross-section (2a) at 100×, surface area: $(\mathbf{2 b})$ at $100 \times,(\mathbf{2 c})$ at $500 \times,(\mathbf{2 d})$ at 25,000 $\times$; GA-crosslinked CS beads after adsorption of the RB4 dye, cross-section (3a) at $100 \times$, surface area: (3b) at $100 \times,(3 \mathbf{c})$ at $500 \times,(3 \mathbf{d})$ at 25,000 $\times$.

On the other hand, the FT-IR spectrum of the CS beads without crosslinking (Figure 8A) shows characteristic broadband at $3324 \mathrm{~cm}^{-1}$ due to the superposition of the OH's stretching vibrations and $\mathrm{NH}_{2}$ functional groups in CS. Bands at 2875, 1022, and $1370 \mathrm{~cm}^{-1}$ are attributed to stretching vibration $\mathrm{C}-\mathrm{H}, \mathrm{C}-\mathrm{O}, \mathrm{C}-\mathrm{N}$, respectively, indicating the polysaccharide structure of CS [31,34,47]. The band indicated at $1576 \mathrm{~cm}^{-1}$ is due to the bending of the primary amine's N-H bond. A band centered at $1646 \mathrm{~cm}^{-1}$ is assigned to the $\mathrm{C}=\mathrm{O}$ stretching vibration in the amide group's CS due to partial deacetylation of chitin to produce CS [34]. The crosslinking reaction between GA and CS amino groups produces a stretch band around $1650 \mathrm{~cm}^{-1}$ that belongs to the imine bond $(\mathrm{C}=\mathrm{N})$ typical of crosslinking $[34,46]$. This band is observed in the spectrum of GA-crosslinked CS beads (Figure 8B) at $1648 \mathrm{~cm}^{-1}$ overlapping with the vibration band at $1646 \mathrm{~cm}^{-1}$ obtained in the spectrum without cross-linking, and the cross-linking reaction is evidenced by the small increased intensity of the stretch band. A small increase in the $2875 \mathrm{~cm}^{-1}$ band corresponding to the $\mathrm{C}-\mathrm{H}$ crosslinked bond is overlapped with the $-\mathrm{CH}_{2}$ - groups in the GA structure. In general, the spectrum showed an increase in intensity in the bands attributed to the bands generated by the various $\mathrm{CS}$ bonds ( $\mathrm{NH} ; \mathrm{OH}$; $\mathrm{CO}$ ) overlapped with the GA structure's bonding groups [31]. 


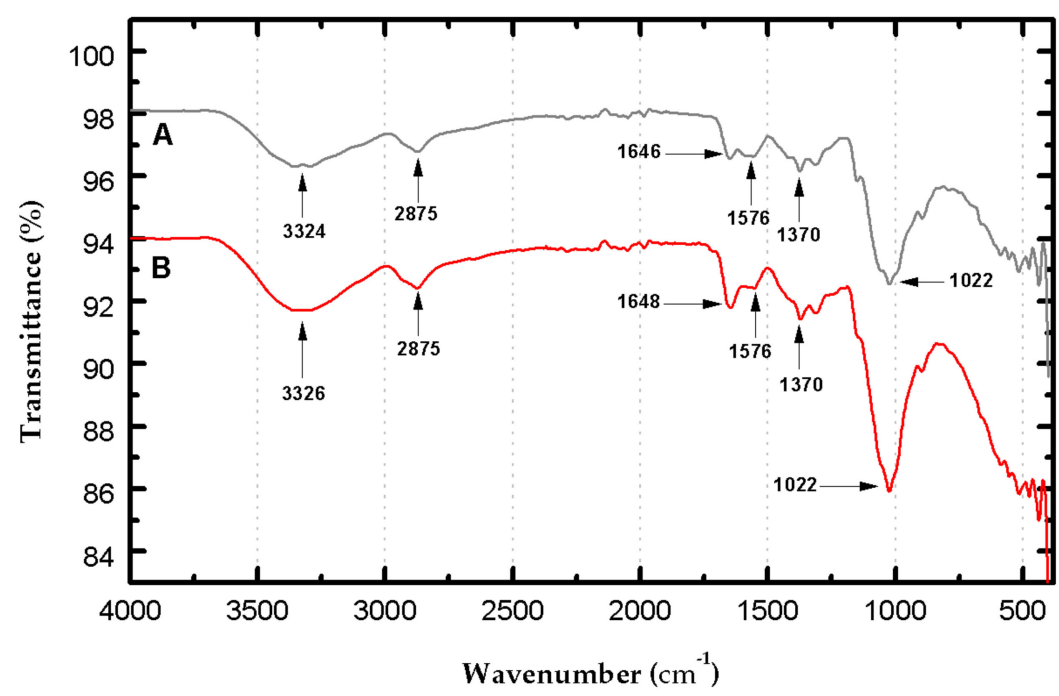

Figure 8. FT-IR spectrum of non-crosslinked CS beads (A) and GA-crosslinked CS beads (B).

Finally, the X-ray diffraction pattern of the non-reticulated CS beads (Figure 9) presented three peaks at $2 \theta$ values of $10^{\circ}, 20^{\circ}$, and $41^{\circ}$, revealing the existence of amorphous regions and high crystallinity. This result is consistent with previous studies reported in the literature [23,48-51].

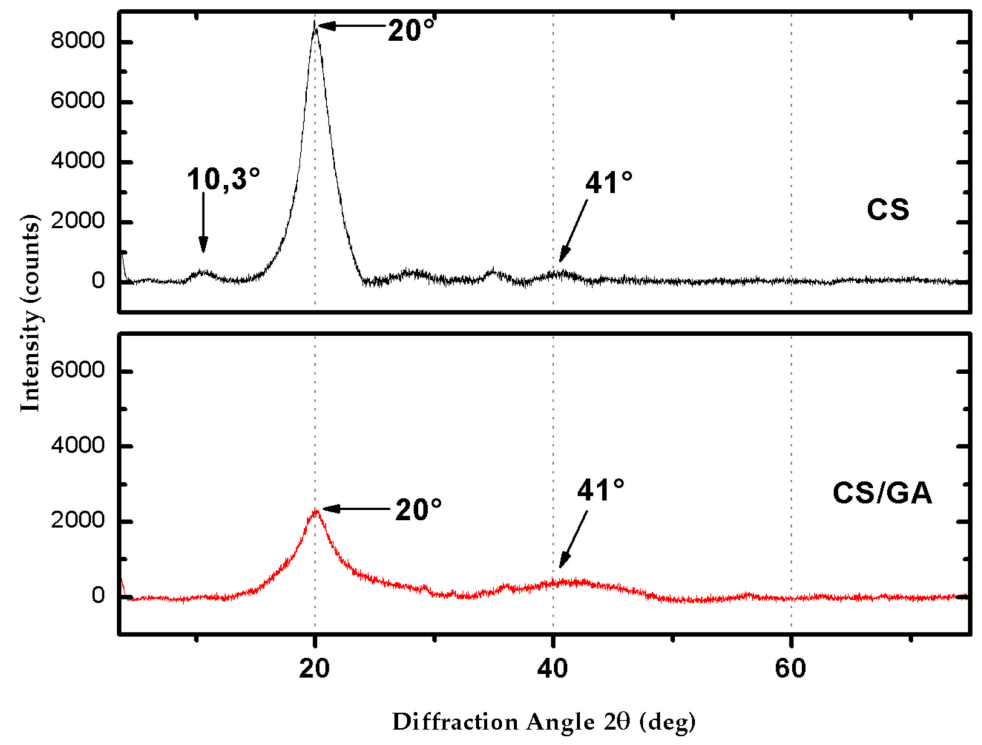

Figure 9. X-ray diffractogram of non-crosslinked CS beads (upper-black line) and GA-crosslinked CS beads (lower-red line).

The high crystallinity is due to the arranged saccharide structure since the hydroxyl and amino groups could form strong intermolecular and intramolecular hydrogen bonds [52].

Furthermore, the structure of CS molecules has a certain regularity. As a result, CS molecules form crystalline regions $[51,53]$. In crosslinking CS with GA, it was observed that the peak seen in the CS spectrum at $2 \theta=10.3^{\circ}$ disappeared, and the peak at $2 \theta=20^{\circ}$ considerably decreased its intensity. According to previous studies [52,54,55], the GA-crosslinked CS beads' crystallinity decreases concerning the unmodified CS. This crystallinity reduction could be attributed to the strong hydrogen bond's deformation in the original CS due to hydroxyl and amino groups' substitution, resulting in an amorphous structure [53]. The beads' crystallinity index (Xc) showed values of $25 \%$ for the non-crosslinked CS and $16 \%$ for the GA-crosslinked CS. This confirms that the addition of a component, such as 
GA, decreases the crystallinity of CS, since it inhibits the folding of the polymer chains responsible for producing crystalline regions in the polymeric network [51].

\subsection{Kinetic Model Analysis}

To determine the kinetic model that best fits the experimental data and describes the adsorption mechanism, the non-linear models of pseudo-first order (PFO), pseudo-second order (PSO), Elovich, and intraparticle diffusion were analyzed. Figure 10 shows the fit of the kinetic models. The values obtained from the maximum adsorption capacities, the speed constants, and the regression coefficient for each model are presented in Table 5.
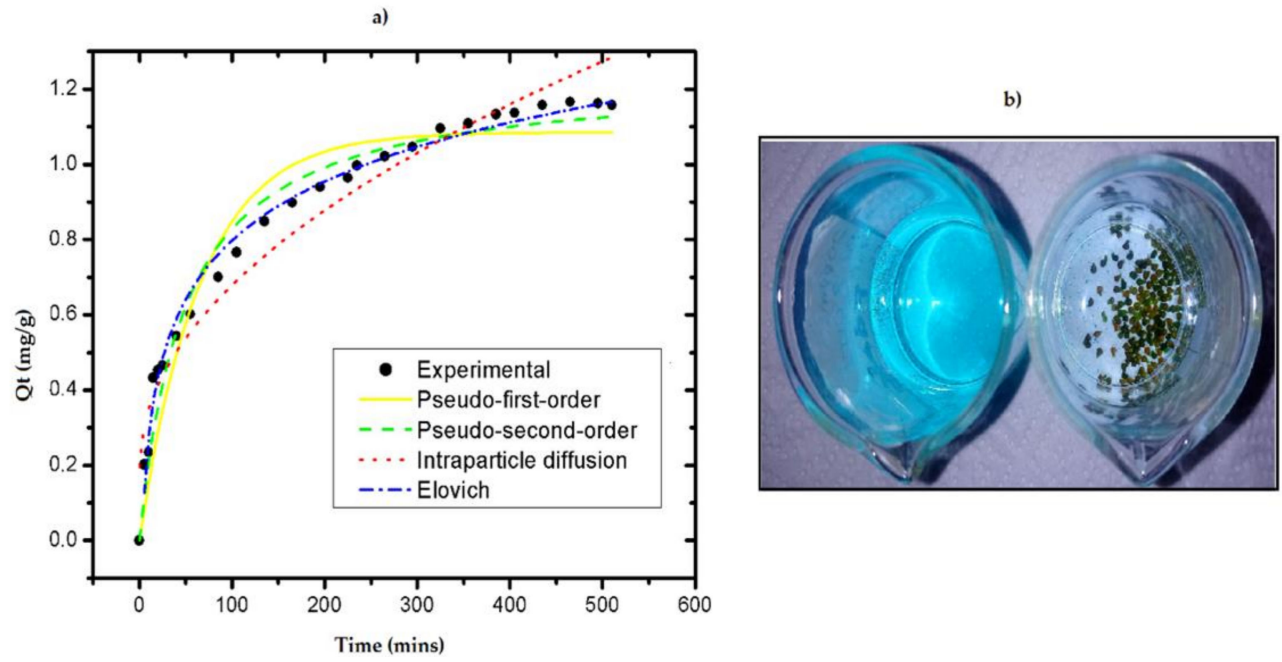

Figure 10. (a) Adsorption kinetics adjusted to different models for RB4 dye; (b) aqueous solution of RB4 dye before and after the adsorption process with GA-crosslinked CS beads. (Initial concentration of $\mathrm{RB} 4$ dye $=35 \mathrm{mg} / \mathrm{L} ; \mathrm{pH}=3.0$; adsorbent dose $=0.4 \mathrm{~g}$; solution volume $=25 \mathrm{~mL}$; constant stirring = $400 \mathrm{rpm}$; temperature $=25^{\circ} \mathrm{C}$ ).

Table 5. Kinetics model parameters for RB4 dye adsorption on GA-crosslinked CS beads.

\begin{tabular}{|c|c|c|c|}
\hline Model & Par & ters & Adj.- $R^{2}$ \\
\hline PFO & $\begin{array}{c}q_{e}(\mathrm{mg} / \mathrm{g}) \\
1.08558\end{array}$ & $\begin{array}{c}K_{1}\left(\min ^{-1}\right) \\
0.01522\end{array}$ & 0.9287 \\
\hline PSO & $\begin{array}{c}q_{e}(\mathrm{mg} / \mathrm{g}) \\
1.23559\end{array}$ & $\begin{array}{c}K_{2}\left(\mathrm{~g} *(\mathrm{mg} * \mathrm{~min})^{-1}\right) \\
0.01646\end{array}$ & 0.9720 \\
\hline Intraparticle diffusion & $\begin{array}{c}K_{i}\left(\mathrm{mg} / \mathrm{g} * \min ^{-0.5}\right) \\
0.04812\end{array}$ & $\begin{array}{c}C(\mathrm{mg} / \mathrm{g}) \\
0.19723\end{array}$ & 0.9484 \\
\hline Elovich & $\begin{array}{c}\alpha(\mathrm{mg} / \mathrm{g} * \min ) \\
0.07708\end{array}$ & $\begin{array}{c}\beta(\mathrm{mg} / \mathrm{g}) \\
4.42261\end{array}$ & 0.9893 \\
\hline
\end{tabular}

PFO: pseudo-first order; PSO: pseudo-second order.

The experimental results showed that the adsorption equilibrium time is reached at $465 \mathrm{~min}$, which corresponded to an $87 \%$ removal efficiency and an adsorption capacity of $1.16 \mathrm{mg} / \mathrm{g}$. Of the models applied in the kinetics, the Elovich model better fit because of the highest determination coefficient and represents the adsorption kinetics of the RB4 dye on the GA-crosslinked CS beads. The constant $\alpha\left(\mathrm{mg} \mathrm{g}^{-1} \mathrm{~min}^{-1}\right)$ corresponds to the initial adsorption rate, and $\beta$ is related to the degree of coverage and activation energy of the surface [41]. Elovich's model suggests that the chemisorption mechanism controlled the dye's adsorption process on the beads and the adsorption rate decreased with time due to more generous coverage on the surface $[41-43,56,57]$. 


\subsection{Adsorption Mechanism of RB4 Dye}

The adsorption mechanism of the RB4 dye on the surface of the GA-crosslinked CS beads is shown in Figure 11. The electrostatic attractions between the negatively charged sulfonate groups $\left(\mathrm{SO}_{3}{ }^{-}\right)$of the $\mathrm{RB} 4$ dye with the amino group $\left(\mathrm{NH}_{3}{ }^{+}\right)$and the positively charged hydroxyl group $\left(\mathrm{HO}^{+}-\mathrm{H}\right)$ available on the surface GA-crosslinked CS beads are favored when the total "charge" of CS adsorbent is highly cationic, due to the stronger protonation of functional groups at acid $\mathrm{pH}$ [58]. Other interactions that take place, to a lesser extent, in the adsorption mechanism are the formation of dipole-dipole bonds, the Yoshida bond, and n-pi interactions [46,59-62].

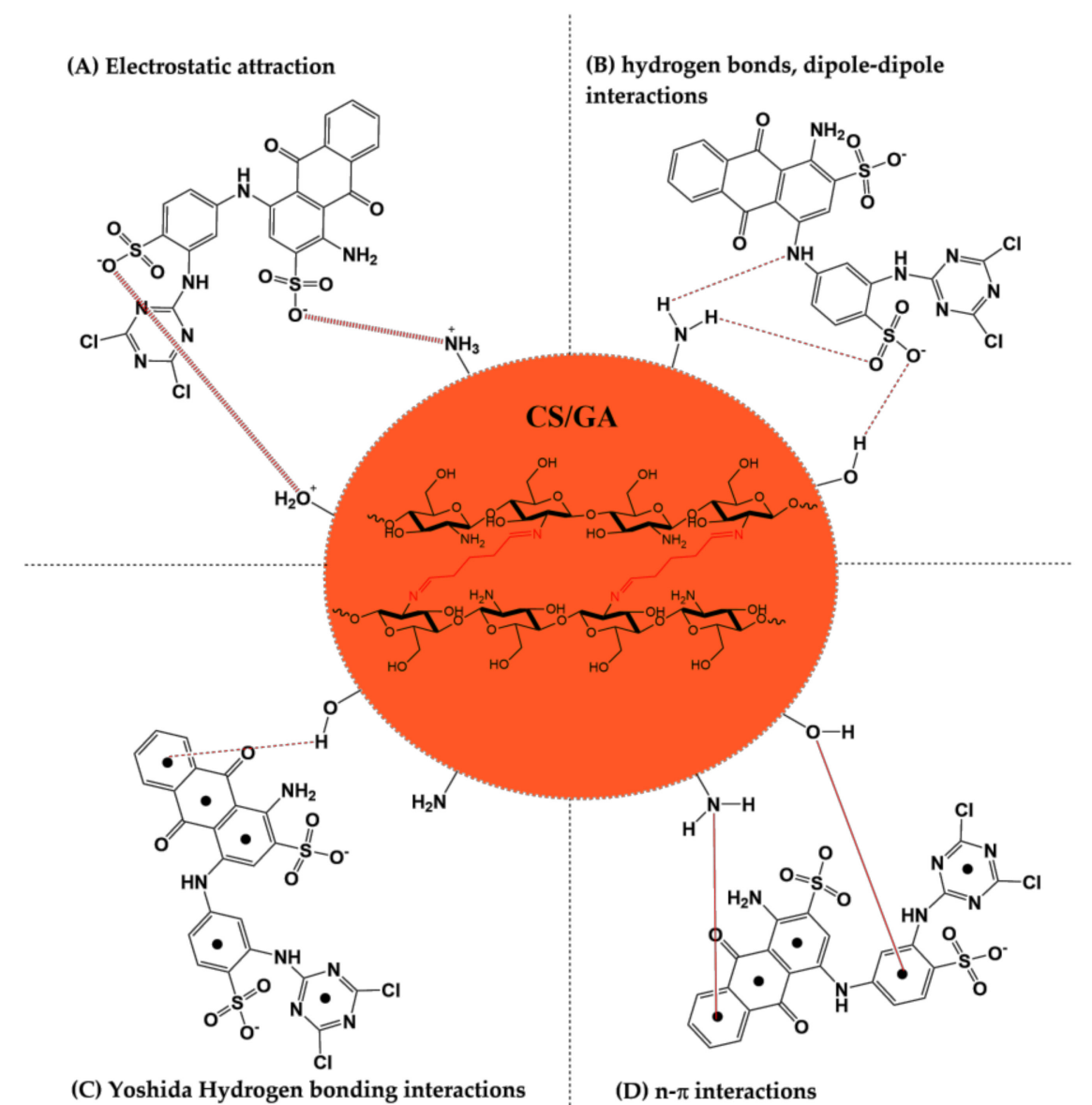

Figure 11. Illustration of the possible interactions between GA-crosslinked CS beads (CS/GA) and RB4 dye: (A) electrostatic attraction, (B) hydrogen bonds dipole-dipole interactions, (C) Yoshida hydrogen bonding interactions, (D) $n-\pi$ interactions.

\subsection{Isothermal Adsorption Equilibrium}

Figure 12 shows the isothermal models (Langmuir, Freundlich, Temkin) used to analyze the RB4 dye adsorption's equilibrium characteristics. The parameters obtained for each model are presented in Table 6. 


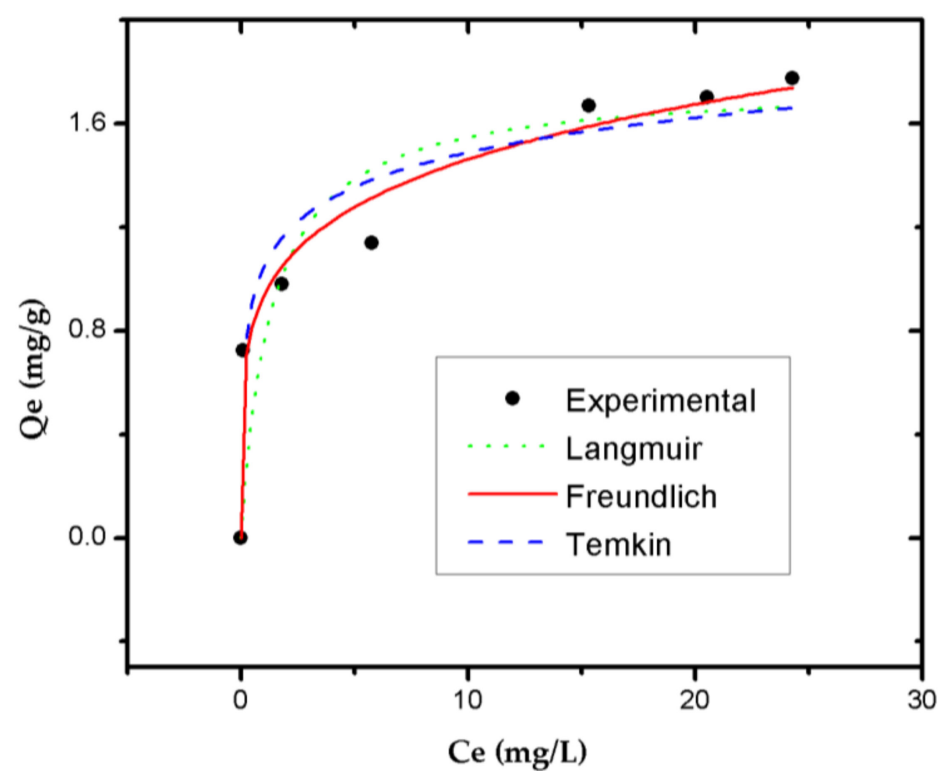

Figure 12. Equilibrium adsorption adjusted to different isothermal models for RB4 dye adsorption on GA-crosslinked CS beads (Initial concentration of $\mathrm{RB} 4$ dye $=35 \mathrm{mg} / \mathrm{L} ; \mathrm{pH}=3.0$; adsorbent dose = $0.4 \mathrm{~g} / 25 \mathrm{~mL}$; constant stirring $=400 \mathrm{rpm}$; temperature $=25^{\circ} \mathrm{C}$ ).

Table 6. Equilibrium models and their calculated parameters for RB4 dye adsorption on GAcrosslinked CS beads.

\begin{tabular}{cccc}
\hline Model & \multicolumn{2}{c}{ Parameters } & Adj.- $\mathbf{R}^{\mathbf{2}}$ \\
\hline \multirow{2}{*}{ Langmuir } & $q_{m}(\mathrm{mg} / \mathrm{g})$ & $K_{\mathrm{L}}(\mathrm{L} / \mathrm{mg})$ & 0.7736 \\
& 1.756 & 0.747 & \\
Freundlich & $n$ & $K_{F}$ & 0.9708 \\
& 5.121 & {$\left[(\mathrm{mg} / \mathrm{g})\left(\mathrm{mg} * \mathrm{~L}^{-1 / \mathrm{n}}\right]\right.$} & \\
Temkin & $K_{t}(\mathrm{~L} / \mathrm{mg})$ & 0.933 & 0.8597 \\
\hline
\end{tabular}

The Freundlich isotherm model provided a better fit with the experimental equilibrium data. This indicated that the system's adsorption process is not limited by generating the monolayer of molecules of the RB4 dye. Instead, there is a heterogeneous distribution of the active sites on the GA-crosslinked CS beads' surface. The constant $K_{F}$ of the model indicated an adsorption capacity of 0.933 when equilibrium was reached. In this sense, the most attractive junction sites occupied the first spaces, and the energy of adsorption decreased with the increasing degree of occupancy of the active adsorption sites [42,63,64]. The parameter n, known as the adsorption intensity, indicated the system's adsorption process's favorability. As $1<\mathrm{n}(5.121)<10$, it was determined that the GA-crosslinked CS beads exhibited good adsorption characteristics $[65,66]$. Table 7 shows that the chemisorption mechanism can control the adsorption processes of RB4 against various adsorbents. Likewise, the distribution of the molecules between the liquid and solid phase depends on the adsorbent's affinities with RB4.

The sorption capacities obtained by various adsorbents in the removal of RB4 are compared in Table 8. In the first place, the adsorbents described exhibit different values in their maximum adsorption capacities due to the treatment's effectiveness depending on the experimental conditions, such as the dose of the adsorbent, the initial concentration of the adsorbate, and the $\mathrm{pH}$, among others. The high doses of the adsorbents favor the overlap of the available surface of the material. Thus, the total effective surface area can decrease, thus decreasing the adsorption [67]. On the other hand, the high initial concentrations of RB4 favor the adsorption capacity since the material's active sites are occupied to a 
greater extent until reaching complete saturation [68]. Likewise, it is evidenced that the adsorption capacity of RB4, in general, is more effective when the $\mathrm{pH}$ takes acid values. In this study, it is reported that the maximum adsorption capacity was 1.56. It is possible that the adsorbent still has active sites for adsorption.

Table 7. Comparison of the kinetic and isothermal models in the adsorption of RB4 in different adsorbents.

\begin{tabular}{|c|c|c|c|}
\hline Adsorbent & Kinetic & Isotherm & Ref. \\
\hline CS/activated charcoal & Pseudo-second order & Langmuir & [67] \\
\hline $\begin{array}{l}\text { Seeds of Moringa } \\
\text { oleifera@ } \mathrm{MnFe}_{2} \mathrm{O}_{4}\end{array}$ & Pseudo-second order & Freundlich & [68] \\
\hline $\begin{array}{l}\text { Microcrystalline } \\
\text { cellulose-epichlorohydrin }\end{array}$ & Pseudo-second order & Langmuir & [69] \\
\hline Polymetallic nanoparticles & Pseudo-second order & Langmuir & [70] \\
\hline $\begin{array}{l}\text { guar gum and silica } \\
\text { nanocomposite }\end{array}$ & $\begin{array}{l}\text { Pseudo-second order and } \\
\text { intraparticle diffusion }\end{array}$ & Langmuir & [71] \\
\hline Pecan nutshells & Pseudo-second order & Langmuir & [72] \\
\hline Rice bran $/ \mathrm{Fe}_{3} \mathrm{O}_{4}$ & Pseudo-second order & Langmuir & [73] \\
\hline CS/hexadecylamine & Pseudo-second order & Freundlich & [20] \\
\hline $\begin{array}{l}\text { CS/hexadecylamine } \\
\text { /3-aminopropyl triethoxysilane }\end{array}$ & Pseudo-second order & Freundlich & [74] \\
\hline CS/3-aminopropyl triethoxysilane & Pseudo-second order & Freundlich & [35] \\
\hline GA-crosslinked CS beads & Elovich & Freundlich & This study \\
\hline
\end{tabular}

Table 8. Comparison of the adsorption capacities of various materials for the removal of RB4.

\begin{tabular}{|c|c|c|c|c|c|}
\hline Adsorbent & $\begin{array}{c}\text { Adsorbent } \\
\text { Concentration } \\
(\mathrm{g} / \mathrm{L})\end{array}$ & $\begin{array}{c}\text { Adsorbate } \\
\text { Concentration } \\
(\mathrm{mg} / \mathrm{L})\end{array}$ & $\mathrm{pH}$ & $\begin{array}{c}\text { Maximum } \\
\text { Adsorption } \\
\text { Capacity (mg/g) }\end{array}$ & Ref. \\
\hline Coconut shells (biomass) & 10 & 1.274 & 5 & 0.0064 & [75] \\
\hline Cauliflower cores (biomass) & 10 & 1.274 & 5 & 0.032 & [75] \\
\hline CS/activated Charcoal & $0.1 / 0.1$ & 100 & 7 & 250 & [67] \\
\hline $\begin{array}{l}\text { Microcrystalline } \\
\text { cellulose-epichlorohydrin }\end{array}$ & 1.0 & 200 & 3 & 70 & [69] \\
\hline Dry cells of Rhizopus oryzae & 4.0 & 100 & 3 & 24 & [76] \\
\hline Polymetallic nanoparticles & 0.4 & 200 & 8.5 & 345 & [70] \\
\hline guar gum and silica nanocomposite & $0.03 / 0.025$ & 200 & 2 & 579 & [71] \\
\hline Pecan nut shells & 10 & 1000 & 6.5 & 5 & {$[72]$} \\
\hline $\begin{array}{c}\mathrm{La}(\mathrm{III}) \text { supported } \\
\text { carboxymethylcellulose-clay }\end{array}$ & 0.1 & 50 & 3 & 43.65 & [77] \\
\hline Rice bran $/ \mathrm{Fe}_{3} \mathrm{O}_{4}$ & 1.5 & 200 & 2 & 185.2 & [73] \\
\hline Rice bran $/ \mathrm{SnO}_{2} / \mathrm{Fe}_{3} \mathrm{O}_{4}$ & 1.5 & 200 & 2 & 218.8 & [78] \\
\hline Nickel-metal hydride spent batteries & 0.80 & 200 & 3 & 331 & [79] \\
\hline Seeds of moringa oleifera@ $\mathrm{MnFe}_{2} \mathrm{O}_{4}$ & $0.1 / 0.05$ & 50 & 3 & 32.45 & [68] \\
\hline CS/hexadecylamine & $0.2 / 0.2$ & 500 & 4 & 454 & [22] \\
\hline CS/3-aminopropyl triethoxysilane Beads & $0.2 / 0.2$ & 500 & 4 & 433.7 & {$[35]$} \\
\hline $\begin{array}{c}\text { CS/hexadecylamine/3-aminopropyl } \\
\text { triethoxysilane }\end{array}$ & $0.2 / 0.2$ & 500 & 4 & 468.8 & [74] \\
\hline Extracellular polymeric substances & $0.1 / 0.05$ & 50 & 2 & 42.93 & [80] \\
\hline CS 10B (100\% deacetylated chitin) & $0.05 / 0.025$ & 63.74 & 4 & 54,01 & [81] \\
\hline CS/hydroxyapatite & 0.03 & 950 & 4 & 118.4 & [82] \\
\hline GA-crosslinked CS beads & $0.4 / 0.025$ & 55 & 3 & 1.56 & This study \\
\hline
\end{tabular}

\section{Conclusions}

The present study experimentally demonstrated that RSM designs allow locating the most suitable conditions where the response is maximized. The mathematical models obtained in the RSM designs provided good fits with the experimental data at a 95\% 
confidence level. A maximum predicted value of $60.65 \%$ was obtained for the experimental design, where the swelling degree was applied as a response variable. Likewise, it was found that the GA cross-linked CS beads increased their degree of swelling at acidic $\mathrm{pH}$ due to the protonation of the amino groups on the beads, which acted as repulsive forces between the polymer chains. The complete elimination of RB4 was achieved in the experimental design's elimination efficiency.

The crosslinking reaction produced between CS and GA was demonstrated through SEM images, which showed the crosslinking's rough surface characteristic. Crystallinity and chemical structure changes were confirmed by XRD and FTIR spectra. The existence of amorphous and high crystallinity regions of the CS beads was identified at values of $2 \theta=10^{\circ}, 20^{\circ}$, and $41^{\circ}$. When crosslinking with GA occurred, a loss of crystallinity occurred, eliminating the peak at $10^{\circ}$ and decreasing the peak at $20^{\circ}$. The crystallinity index also confirmed the decrease in the non-crosslinking CS's crystallinity from $25 \%$ to $16 \%$ with the crosslinking agent's addition. In the FTIR, beads' crosslinking was supported by an imine bond stretching band $(\mathrm{C}=\mathrm{N})$ at $1648 \mathrm{~cm}^{-1}$ that was found to overlap with the vibration band of $1646 \mathrm{~cm}^{-1}$ the functional group $\mathrm{C}=\mathrm{O}$. The adsorption kinetics suggested that the interaction mechanism was controlled by chemisorption. The equilibrium data indicated that the RB4 molecules are heterogeneously distributed in the active sites on the CS/GA beads' surface. Finally, the GA crosslinked beads presented in this work can act as an ecological adsorbent, capable of efficiently removing anionic dyes in water bodies.

Supplementary Materials: The following are available online at https:/ / www.mdpi.com/2075-172 9/11/2/85/s1. Table S1. Models of adsorption kinetics. Table S2. Adsorption isotherm models.

Author Contributions: Conceptualization, J.T., V.A.A., and C.D.G.-T.; data curation, J.G.; formal analysis, V.A.A. and C.D.G.-T.; investigation, J.G., J.T., P.A.Z., V.A.A., and C.D.G.-T.; methodology, J.G., P.A.Z., V.A.A., C.D.G.-T.; writing-original draft, J.G.; writing-review and editing, J.T., P.A.Z., V.A.A., and C.D.G.-T. All authors have read and agreed to the published version of the manuscript.

Funding: This research received no external funding.

Institutional Review Board Statement: Not applicable

Informed Consent Statement: Informed consent was obtained from all subjects involved in the study.

Data Availability Statement: Not applicable

Acknowledgments: P.A. Zapata acknowledges the financial support under FONDECYT Regular Project 1170226.

Conflicts of Interest: The authors declare no conflict of interest.

\section{References}

1. Alver, E.; Metin, A.Ü. Anionic dye removal from aqueous solutions using modified zeolite: Adsorption kinetics and isotherm studies. Chem. Eng. J. 2012, 200, 59-67. [CrossRef]

2. Mezohegyi, G.; van der Zee, F.P.; Font, J.; Fortuny, A.; Fabregat, A. Towards advanced aqueous dye removal processes: A short review on the versatile role of activated carbon. J. Environ. Manag. 2012, 102, 148-164. [CrossRef] [PubMed]

3. Greluk, M.; Hubicki, Z. Efficient removal of Acid Orange 7 dye from water using the strongly basic anion exchange resin Amberlite IRA-958. Desalination 2011, 278, 219-226. [CrossRef]

4. Chowdhury, S.; Mishra, R.; Saha, P.; Kushwaha, P. Adsorption thermodynamics, kinetics and isosteric heat of adsorption of malachite green onto chemically modified rice husk. Desalination 2011, 265, 159-168. [CrossRef]

5. Allen, S.J.; Mckay, G.; Porter, J.F. Adsorption isotherm models for basic dye adsorption by peat in single and binary component systems. J. Colloid Interface Sci. 2004, 280, 322-333. [CrossRef]

6. Wakankar, D.M. Regulations relating to the use of textile dyes and chemicals. In Advances in the Dyeing and Finishing of Technical Textiles; Elsevier: Amsterdam, The Netherlands, 2013; pp. 105-132.

7. Pierce, J. Colour in textile effluents-the origins of the problem. J. Soc. Dye. Colour. 1994, 110, 131-133. [CrossRef]

8. Sakkayawong, N.; Thiravetyan, P.; Nakbanpote, W. Adsorption mechanism of synthetic reactive dye wastewater by chitosan. J. Colloid Interface Sci. 2005, 286, 36-42. [CrossRef] 
9. Ngah, W.S.W.; Liew, L.A.I. Chitosan and chemically modified chitosan beads for acid dyes sorption. J. Environ. Sci. 2009, 21, 296-302.

10. Santos, P.B.; Santos, J.J.; Corrêa, C.C.; Corio, P.; Andrade, G.F.S. Plasmonic photodegradation of textile dye Reactive Black 5 under visible light: A vibrational and electronic study. J. Photochem. Photobiol. A Chem. 2019, 371, 159-165. [CrossRef]

11. Wu, F.-C.; Tseng, R.-L.; Juang, R.-S. A review and experimental verification of using chitosan and its derivatives as adsorbents for selected heavy metals. J. Environ. Manage. 2010, 91, 798-806. [CrossRef]

12. Crini, G.; Badot, P.-M. Application of chitosan, a natural aminopolysaccharide, for dye removal from aqueous solutions by adsorption processes using batch studies: A review of recent literature. Prog. Polym. Sci. 2008, 33, 399-447. [CrossRef]

13. Muzzarelli, R.A.A.; Boudrant, J.; Meyer, D.; Manno, N.; DeMarchis, M.; Paoletti, M.G. Current views on fungal chitin/chitosan, human chitinases, food preservation, glucans, pectins and inulin: A tribute to Henri Braconnot, precursor of the carbohydrate polymers science, on the chitin bicentennial. Carbohydr. Polym. 2012, 87, 995-1012. [CrossRef]

14. Luk, C.J.; Yip, J.; Yuen, C.M.; Kan, C.; Lam, K. A comprehensive study on adsorption behaviour of direct, reactive and acid dyes on crosslinked and non-crosslinked chitosan beads. J. Fiber Bioeng. Inform. 2014, 7, 35-52.

15. Miretzky, P.; Cirelli, A.F. Hg (II) removal from water by chitosan and chitosan derivatives: A review. J. Hazard. Mater. 2009, 167, 10-23. [CrossRef] [PubMed]

16. Filipkowska, U. Effectiveness of dye adsorption onto non-cross-linked and cross-linked chitosan beads. Prog. Chem. Appl. Chitin Deriv. 2012, 17, 43-52.

17. Ngah, W.S.W.; Fatinathan, S. Chitosan flakes and chitosan-GLA beads for adsorption of p-nitrophenol in aqueous solution. Colloids Surf. A Physicochem. Eng. Asp. 2006, 277, 214-222. [CrossRef]

18. Chae, S.Y.; Jang, M.-K.; Nah, J.-W. Influence of molecular weight on oral absorption of water soluble chitosans. J. Control. Release 2005, 102, 383-394. [CrossRef]

19. Bof, M.J.; Bordagaray, V.C.; Locaso, D.E.; García, M.A. Chitosan molecular weight effect on starch-composite film properties. Food Hydrocoll. 2015, 51, 281-294. [CrossRef]

20. Statgraphics Centurion XVI. Statpoint Technologies. 2009. Available online: https://www.statgraphics.com (accessed on 15 December 2020).

21. Montgomery, C.D. Montgomery Design and Analysis of Experiments; John Wiley \& Sons Inc.: Hoboken, NJ, USA, 1997; ISBN 0471316490.

22. Vakili, M.; Rafatullah, M.; Ibrahim, M.H.; Abdullah, A.Z.; Salamatinia, B.; Gholami, Z. Chitosan hydrogel beads impregnated with hexadecylamine for improved reactive blue 4 adsorption. Carbohydr. Polym. 2016, 137, 139-146. [CrossRef]

23. Karthikeyan, P.; Banu, H.A.T.; Meenakshi, S. Synthesis and characterization of metal loaded chitosan-alginate biopolymeric hybrid beads for the efficient removal of phosphate and nitrate ions from aqueous solution. Int. J. Biol. Macromol. 2019, 130, 407-418. [CrossRef]

24. Nara, S.; Komiya, T. Studies on the relationship between water-satured state and crystallinity by the diffraction method for moistened potato starch. Starch-Stärke 1983, 35, 407-410. [CrossRef]

25. Mohammad, A.-T.; Abdulhameed, A.S.; Jawad, A.H. Box-Behnken design to optimize the synthesis of new crosslinked chitosanglyoxal/TiO2 nanocomposite: Methyl orange adsorption and mechanism studies. Int. J. Biol. Macromol. 2019, 129, 98-109. [CrossRef] [PubMed]

26. Sohbatzadeh, H.; Keshtkar, A.R.; Safdari, J.; Fatemi, F. U (VI) biosorption by bi-functionalized Pseudomonas putida@ chitosan bead: Modeling and optimization using RSM. Int. J. Biol. Macromol. 2016, 89, 647-658. [CrossRef]

27. Gutiérrez Pulido, H.; de la Vara Salazar, R. Análisis y Diseño de Experimentos; McGraw Hill: New York, NY, USA, 2004.

28. Jóźwiak, T.; Filipkowska, U. Sorption kinetics and isotherm studies of a Reactive Black 5 dye on chitosan hydrogel beads modified with various ionic and covalent cross-linking agents. J. Environ. Chem. Eng. 2020, 8, 103564. [CrossRef]

29. Tasselli, F.; Mirmohseni, A.; Dorraji, M.S.S.; Figoli, A. Mechanical, swelling and adsorptive properties of dry-wet spun chitosan hollow fibers crosslinked with glutaraldehyde. React. Funct. Polym. 2013, 73, 218-223. [CrossRef]

30. Zhao, F.; Yu, B.; Yue, Z.; Wang, T.; Wen, X.; Liu, Z.; Zhao, C. Preparation of porous chitosan gel beads for copper (II) ion adsorption. J. Hazard. Mater. 2007, 147, 67-73. [CrossRef] [PubMed]

31. Kildeeva, N.R.; Perminov, P.A.; Vladimirov, L.V.; Novikov, V.V.; Mikhailov, S.N. About mechanism of chitosan cross-linking with glutaraldehyde. Russ. J. Bioorganic Chem. 2009, 35, 360-369. [CrossRef]

32. Bui, T.H.; Lee, W.; Jeon, S.; Kim, K.-W.; Lee, Y. Enhanced Gold (III) Adsorption Using Glutaraldehyde-Crosslinked Chitosan Beads: Effect of Crosslinking Degree on Adsorption Selectivity, Capacity, and Mechanism. Sep. Purif. Technol. 2020, 116989. [CrossRef]

33. Poon, L.; Wilson, L.D.; Headley, J.V. Chitosan-glutaraldehyde copolymers and their sorption properties. Carbohydr. Polym. 2014, 109, 92-101. [CrossRef]

34. Nematidil, N.; Sadeghi, M.; Nezami, S.; Sadeghi, H. Synthesis and characterization of Schiff-base based chitosan-gglutaraldehyde/NaMMTNPs-APTES for removal $\mathrm{Pb}^{2+}$ and $\mathrm{Hg}^{2+}$ ions. Carbohydr. Polym. 2019, 222, 114971. [CrossRef]

35. Vakili, M.; Rafatullah, M.; Salamatinia, B.; Ibrahim, M.H.; Abdullah, A.Z. Elimination of reactive blue 4 from aqueous solutions using 3-aminopropyl triethoxysilane modified chitosan beads. Carbohydr. Polym. 2015, 132, 89-96. [CrossRef] [PubMed]

36. Sohni, S.; Hashim, R.; Nidaullah, H.; Lamaming, J.; Sulaiman, O. Chitosan/nano-lignin based composite as a new sorbent for enhanced removal of dye pollution from aqueous solutions. Int. J. Biol. Macromol. 2019, 132, 1304-1317. [CrossRef] [PubMed] 
37. Huang, R.; Liu, Q.; Huo, J.; Yang, B. Adsorption of methyl orange onto protonated cross-linked chitosan. Arab. J. Chem. 2017, 10, 24-32. [CrossRef]

38. Pakdel, P.M.; Peighambardoust, S.J. Review on recent progress in chitosan-based hydrogels for wastewater treatment application. Carbohydr. Polym. 2018, 201, 264-279. [CrossRef]

39. Correia, V.M.; Stephenson, T.; Judd, S.J. Characterisation of textile wastewaters-a review. Environ. Technol. 1994, 15, 917-929. [CrossRef]

40. Jiang, X.; Sun, Y.; Liu, L.; Wang, S.; Tian, X. Adsorption of CI Reactive Blue 19 from aqueous solutions by porous particles of the grafted chitosan. Chem. Eng. J. 2014, 235, 151-157. [CrossRef]

41. Wu, F.-C.; Tseng, R.-L.; Juang, R.-S. Characteristics of Elovich equation used for the analysis of adsorption kinetics in dye-chitosan systems. Chem. Eng. J. 2009, 150, 366-373. [CrossRef]

42. Chang, M.-Y.; Juang, R.-S. Equilibrium and kinetic studies on the adsorption of surfactant, organic acids and dyes from water onto natural biopolymers. Colloids Surf. A Physicochem. Eng. Asp. 2005, 269, 35-46. [CrossRef]

43. Jaafari, J.; Barzanouni, H.; Mazloomi, S.; Farahani, N.A.A.; Sharafi, K.; Soleimani, P.; Haghighat, G.A. Effective adsorptive removal of reactive dyes by magnetic chitosan nanoparticles: Kinetic, isothermal studies and response surface methodology. Int. J. Biol. Macromol. 2020, 164, 344-355. [CrossRef]

44. Salem, M.A.; Elsharkawy, R.G.; Ayad, M.I.; Elgendy, M.Y. Silver nanoparticles deposition on silica, magnetite, and alumina surfaces for effective removal of Allura red from aqueous solutions. J. Sol-Gel Sci. Technol. 2019, 91, 523-538. [CrossRef]

45. Kamari, A.; Ngah, W.S.W.; Chong, M.Y.; Cheah, M.L. Sorption of acid dyes onto GLA and $\mathrm{H}_{2} \mathrm{SO}_{4}$ cross-linked chitosan beads. Desalination 2009, 249, 1180-1189. [CrossRef]

46. Jawad, A.H.; Mubarak, N.S.A.; Abdulhameed, A.S. Tunable Schiff's base-cross-linked chitosan composite for the removal of reactive red 120 dye: Adsorption and mechanism study. Int. J. Biol. Macromol. 2020, 142, 732-741. [CrossRef] [PubMed]

47. Hansraj, G.P.; Singh, S.K.; Kumar, P. Sumatriptan succinate loaded chitosan solid lipid nanoparticles for enhanced anti-migraine potential. Int. J. Biol. Macromol. 2015, 81, 467-476. [CrossRef] [PubMed]

48. Omidi, S.; Kakanejadifard, A. Eco-friendly synthesis of graphene-chitosan composite hydrogel as efficient adsorbent for Congo red. RSC Adv. 2018, 8, 12179-12189. [CrossRef]

49. Abdelkrim, S.; Mokhtar, A.; Djelad, A.; Bennabi, F.; Souna, A.; Bengueddach, A.; Sassi, M. Chitosan/Ag-bentonite nanocomposites: Preparation, characterization, swelling and biological properties. J. Inorg. Organomet. Polym. Mater. 2020, 30, 831-840. [CrossRef]

50. Cestari, A.R.; Vieira, E.F.S.; Dos Santos, A.G.P.; Mota, J.A.; de Almeida, V.P. Adsorption of anionic dyes on chitosan beads. 1. The influence of the chemical structures of dyes and temperature on the adsorption kinetics. J. Colloid Interface Sci. 2004, 280, 380-386. [CrossRef]

51. Garnica-Palafox, I.M.; Sánchez-Arévalo, F.M. Influence of natural and synthetic crosslinking reagents on the structural and mechanical properties of chitosan-based hybrid hydrogels. Carbohydr. Polym. 2016, 151, 1073-1081. [CrossRef]

52. Saita, K.; Nagaoka, S.; Shirosaki, T.; Horikawa, M.; Matsuda, S.; Ihara, H. Preparation and characterization of dispersible chitosan particles with borate crosslinking and their antimicrobial and antifungal activity. Carbohydr. Res. 2012, 349, 52-58. [CrossRef]

53. Li, B.; Shan, C.-L.; Zhou, Q.; Fang, Y.; Wang, Y.-L.; Xu, F.; Han, L.-R.; Ibrahim, M.; Guo, L.-B.; Xie, G.-L. Synthesis, characterization, and antibacterial activity of cross-linked chitosan-glutaraldehyde. Mar. Drugs 2013, 11, 1534-1552. [CrossRef]

54. Monteiro, O.A.C., Jr.; Airoldi, C. Some studies of crosslinking chitosan-glutaraldehyde interaction in a homogeneous system. Int J. Biol. Macromol. 1999, 26, 119-128. [CrossRef]

55. Tu, N.; Shou, J.; Dong, H.; Huang, J.; Li, Y. Improved catalytic performance of lipase supported on clay/chitosan composite beads. Catalysts 2017, 7, 302. [CrossRef]

56. Dotto, G.L.; Pinto, L.A.A. Adsorption of food dyes onto chitosan: Optimization process and kinetic. Carbohydr. Polym. 2011, 84, 231-238. [CrossRef]

57. Dotto, G.L.; Pinto, L.A.A. Adsorption of food dyes acid blue 9 and food yellow 3 onto chitosan: Stirring rate effect in kinetics and mechanism. J. Hazard. Mater. 2011, 187, 164-170. [CrossRef] [PubMed]

58. Kyzas, G.Z.; Kostoglou, M.; Lazaridis, N.K. Relating interactions of dye molecules with chitosan to adsorption kinetic data. Langmuir 2010, 26, 9617-9626. [CrossRef]

59. Abdulhameed, A.S.; Mohammad, A.-T.; Jawad, A.H. Application of response surface methodology for enhanced synthesis of chitosan tripolyphosphate $/ \mathrm{TiO}_{2}$ nanocomposite and adsorption of reactive orange 16 dye. J. Clean. Prod. 2019, $232,43-56$. [CrossRef]

60. Chatterjee, S.; Chatterjee, S.; Chatterjee, B.P.; Guha, A.K. Adsorptive removal of congo red, a carcinogenic textile dye by chitosan hydrobeads: Binding mechanism, equilibrium and kinetics. Colloids Surf. A Physicochem. Eng. Asp. 2007, 299, 146-152. [CrossRef]

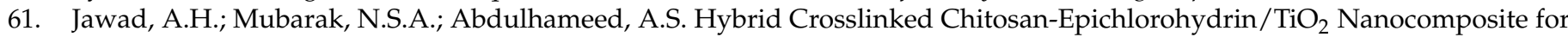
Reactive Red 120 Dye Adsorption: Kinetic, Isotherm, Thermodynamic, and Mechanism Study. J. Polym. Environ. 2020, 28 , 624-637. [CrossRef]

62. Jawad, A.H.; Abdulhameed, A.S.; Abd Malek, N.N.; ALOthman, Z.A. Statistical optimization and modeling for color removal and COD reduction of reactive blue 19 dye by mesoporous chitosan-epichlorohydrin/kaolin clay composite. Int. J. Biol. Macromol. 2020, 164, 4218-4230. [CrossRef]

63. Saha, T.K.; Bhoumik, N.C.; Karmaker, S.; Ahmed, M.G.; Ichikawa, H.; Fukumori, Y. Adsorption characteristics of reactive black 5 from aqueous solution onto chitosan. CLEAN Soil Air Water 2011, 39, 984-993. [CrossRef] 
64. Zeldowitsch, J. Adsorption site energy distribution. Acta Physicochim. URSS 1934, 1, 961-973.

65. Pérez-Calderón, J.; Santos, M.V.; Zaritzky, N. Reactive RED 195 dye removal using chitosan coacervated particles as bio-sorbent: Analysis of kinetics, equilibrium and adsorption mechanisms. J. Environ. Chem. Eng. 2018, 6, 6749-6760. [CrossRef]

66. Mckay, G.; Blair, H.S.; Gardner, J.R. Adsorption of dyes on chitin. I. Equilibrium studies. J. Appl. Polym. Sci. 1982, 27, 3043-3057. [CrossRef]

67. Karaer, H.; Kaya, I. Synthesis, characterization of magnetic chitosan/active charcoal composite and using at the adsorption of methylene blue and reactive blue4. Microporous Mesoporous Mater. 2016, 232, 26-38. [CrossRef]

68. Sirajudheen, P.; Karthikeyan, P.; Ramkumar, K.; Nisheetha, P.; Meenakshi, S. Magnetic carbon-biomass from the seeds of Moringa oleifera@ $\mathrm{MnFe}_{2} \mathrm{O}_{4}$ composite as an effective and recyclable adsorbent for the removal of organic pollutants from water. J. Mol. Liq. 2020, 114829. [CrossRef]

69. Zhai, Y.; Qu, H.; Li, Z.; Zhang, B.; Cheng, J.; Zhang, J. Rapid and Efficient Adsorption Removal of Reactive Blue 4 from Aqueous Solution by Cross-Linked Microcrystalline Cellulose-Epichlorohydrin Polymers: Isothermal, Kinetic, and Thermodynamic Study. Trans. Tianjin Univ. 2020. [CrossRef]

70. Nascimento, M.A.; Cruz, J.C.; Rodrigues, G.D.; de Oliveira, A.F.; Lopes, R.P. Synthesis of polymetallic nanoparticles from spent lithium-ion batteries and application in the removal of reactive blue 4 dye. J. Clean. Prod. 2018, 202, 264-272. [CrossRef]

71. Pal, S.; Patra, A.S.; Ghorai, S.; Sarkar, A.K.; Mahato, V.; Sarkar, S.; Singh, R.P. Efficient and rapid adsorption characteristics of templating modified guar gum and silica nanocomposite toward removal of toxic reactive blue and Congo red dyes. Bioresour. Technol. 2015, 191, 291-299. [CrossRef]

72. Aguayo-Villarreal, I.A.; Ramírez-Montoya, L.A.; Hernández-Montoya, V.; Bonilla-Petriciolet, A.; Montes-Morán, M.A.; RamírezLópez, E.M. Sorption mechanism of anionic dyes on pecan nut shells (Carya illinoinensis) using batch and continuous systems. Ind. Crops Prod. 2013, 48, 89-97. [CrossRef]

73. Hong, G.-B.; Wang, Y.-K. Synthesis of low-cost adsorbent from rice bran for the removal of reactive dye based on the response surface methodology. Appl. Surf. Sci. 2017, 423, 800-809. [CrossRef]

74. Vakili, M.; Rafatullah, M.; Ibrahim, M.H.; Abdullah, A.Z.; Gholami, Z.; Salamatinia, B. Enhancing reactive blue 4 adsorption through chemical modification of chitosan with hexadecylamine and 3-aminopropyl triethoxysilane. J. Water Process Eng. 2017, 15, 49-54. [CrossRef]

75. Landin-Sandoval, V.J.; Mendoza-Castillo, D.I.; Seliem, M.K.; Mobarak, M.; Villanueva-Mejia, F.; Bonilla-Petriciolet, A.; NavarroSantos, P.; Reynel-Ávila, H.E. Physicochemical analysis of multilayer adsorption mechanism of anionic dyes on lignocellulosic biomasses via statistical physics and density functional theory. J. Mol. Liq. 2020, 114511. [CrossRef]

76. Bagchi, M.; Ray, L. Adsorption behavior of Reactive Blue 4, a tri-azine dye on dry cells of Rhizopus oryzae in a batch system. Chem. Speciat. Bioavailab. 2015, 27, 112-120. [CrossRef]

77. Sirajudheen, P.; Karthikeyan, P.; Vigneshwaran, S.; Meenakshi, S. Synthesis and characterization of La(III) supported carboxymethylcellulose-clay composite for toxic dyes removal: Evaluation of adsorption kinetics, isotherms and thermodynamics. Int. J. Biol. Macromol. 2020, 161, 1117-1126. [CrossRef]

78. Ma, C.M.; Hong, G.B.; Wang, Y.K. Performance evaluation and optimization of dyes removal using Rice bran-based magnetic composite adsorbent. Materials 2020, 13, 2764. [CrossRef] [PubMed]

79. Nascimento, M.A.; da Cruz, J.C.; dos Reis, M.F.; Alpino, C.T.C.; Marcelo, C.R.; Rodrigues, G.D.; de Oliveira, A.F.; Lopes, R.P. Synthesis of materials produced from spent batteries with environmental application. Quim. Nova 2020, 43, 1017-1025. [CrossRef]

80. Binupriya, A.R.; Sathishkumar, M.; Ku, C.S.; Yun, S.-I. Sequestration of Reactive Blue 4 by free and immobilized Bacillus subtilis cells and its extracellular polysaccharides. Colloids Surf. B Biointerfaces 2010, 76, 179-185. [CrossRef]

81. Karmaker, S.; Nag, A.J.; Saha, T.K. Adsorption of Reactive Blue 4 Dye onto Chitosan 10B in Aqueous Solution: Kinetic Modeling and Isotherm Analysis. Russ. J. Phys. Chem. A 2020, 94, 2349-2359. [CrossRef]

82. Rastgordani, M.; Zolgharnein, J. Simultaneous Determination and Optimization of Titan Yellow and Reactive Blue 4 Dyes Removal Using Chitosan@hydroxyapatite Nanocomposites. J. Polym. Environ. 2021. [CrossRef] 